\title{
Hydration of Aluminous Cements and Its Relation to the Phase Equilibria in the System Lime-Alumina-Water
}

\author{
Lansing S. Wells* and Elmer T. Carlson
}

\begin{abstract}
A study was made of the reaction of water at room temperature on eight aluminous cements covering a wide range of composition. The results are compared with data previously obtained from similar tests on the calcium aluminates, and are discussed in the light of more recent studies of the system $\mathrm{CaO}-\mathrm{Al}_{2} \mathrm{O}_{3}-\mathrm{H}_{2} \mathrm{O}$. Like the less basic calcium aluminates, the aluminous cements give rise to metastable monocalcium aluminate solutions from which $2 \mathrm{CaO} \cdot \mathrm{Al}_{2} \mathrm{O}_{3} \cdot 8 \mathrm{H}_{2} \mathrm{O}$ and $\mathrm{Al}_{2} \mathrm{O}_{3} \cdot$ aq are gradually precipitated unt the concentration has fallen to about 0.19 gram of $\mathrm{Al}_{2} \mathrm{O}_{3}$ and 0.46 gram of $\mathrm{CaO}$ per liter. From this point,

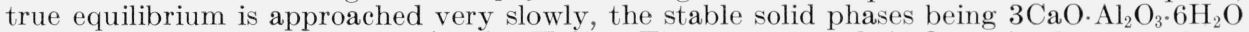
and macrocrystalline gibbsite $\left(\mathrm{Al}_{2} \mathrm{O}_{3} \cdot 3 \mathrm{H}_{2} \mathrm{O}\right)$. The precipitated $\mathrm{Al}_{2} \mathrm{O}_{3}$. aq is shown to be a microcrystalline form of gibbsite. It is suggested that this phase is the principal "inorganic glue" of aluminous cements. The process of aging to macrocrystalline gibbsite is accelerated by increased temperature, and probably is the chief cause of the decreased strength of aluminous cements at higher temperatures.
\end{abstract}

\section{Introduction}

Aluminous cement, also known as bigh-alumina or calcium aluminate cement, is a type of hydraulic cement in which calcium aluminates are the essential constituents. In this respect it differs from portland cement, which consists chiefly of calcium silicates, with smaller amounts of aluminous phases.

The raw materials used for the manufacture of aluminous cements are limestone and bauxite. The most common method of manufacture is by fusion in a reverberatory open-hearth furnace. Electric furnaces have also been used at a number of plants in Europe. Aluminous cement is also produced by fusion in a rotary kiln of a type similar to that used in the manufacture of portland cement. Although sintering processes have been used, the most common practice is to heat the mix to fusion. Generally, the fused material is run into molds and cooled. The pigs of fused cement, after cooling, are crushed, sieved, and passed through a magnetic separator to remove metallic iron, and then ground in tube or ball mills.

A detailed discussion of the history, manufacture, properties, and uses of aluminous cement is given by Lea and Desch [1]. ${ }^{1}$

A relatively recent and important application of aluminous cement is in the manufacture of the so-called "refractory castables" used in steel furnaces and combustion chambers [2]. Mixed with a refractory aggregate, the cement acts initially as a hydraulic binder. When subsequently heated to high temperatures it reacts with the aggregate to form a ceramic bond.

The development of the aluminous-cement industry was accompanied by a number of laboratory investigations, both here and abroad, on the chemistry of the calcium aluminates and aluminous cements. Considerable work in this field was done at the

\section{*Deceased.}

${ }^{1}$ Figures in brackets indicate the literature references at the end of this paper
Bureau. In 1921, Bates [3] published the results of his study of the cementing qualities of the calcium aluminates. He showed that the compounds $\mathrm{CaO} \cdot \mathrm{Al}_{2} \mathrm{O}_{3}$ and $3 \mathrm{CaO} \cdot 5 \mathrm{Al}_{2} \mathrm{O}_{3}$ have satisfactory setting properties, whereas the two more basic aluminates, $5 \mathrm{CaO} \cdot 3 \mathrm{Al}_{2} \mathrm{O}_{3}$ and $3 \mathrm{CaO} \cdot \mathrm{Al}_{2} \mathrm{O}_{3}$, react energetically with water and set too rapidly for practical use. In 1928, Wells [4] published a paper on the mechanism of the reaction of water on the calcium aluminates and on a high-alumina cement. In 1930, Bates [5], at the meeting of the International Association for Testing Materials in Zürich, reported on the composition and properties of aluminous cements from six countries. This investigation was conducted jointly by the National Bureau of Standards and the Atlas Lumnite Cement Co.

The data on which the present paper is based were obtained during the same period, but for various reasons have not hitherto been published. In the meantime, studies of phase equilibria in the system $\mathrm{CaO}-\mathrm{Al}_{2} \mathrm{O}_{3}-\mathrm{H}_{2} \mathrm{O}$, first at ordinary temperatures [6], later at higher temperatures [7], laid the foundation for a better interpretation of the earlier data. Other investigators in the United States and in other countries have contributed greatly to the present knowledge of the aluminous cements. A comprehensive review of the work pertaining to the system $\mathrm{CaO}-\mathrm{Al}_{2} \mathrm{O}_{3}-\mathrm{H}_{2} \mathrm{O}$ was published by Steinour in 1951 [8]. The composition of the anhydrous aluminous cements, and methods for calculating the compound composition from analytical data, were reported on by Parker [9] at the Third International Symposium on the Chemistry of Cement in London in 1952 .

The chemistry of aluminous cement is very complex, and despite the wealth of excellent data on the subject, it cannot yet be said that the setting and hardening of this material are completely understood. The purpose of this paper is to present data relative to the reaction of water on aluminous cements, to attempt to interpret these in the light of present knowledge of the system $\mathrm{CaO}-\mathrm{Al}_{2} \mathrm{O}_{3}-\mathrm{H}_{2} \mathrm{O}$ and the composition of the anhydrous cement, and 
to make certain deductions as to the reactions involved in the setting and subsequent properties of aluminous cements.

\section{Aluminous Cements}

\subsection{Oxide Composition}

The analyses of the eight aluminous cements included in this study are given in table 1 . Six of the cements are of the same brands as those described by Bates [5], but of different lots; the analyses therefore differ slightly from those given by him. Number 7 is a white aluminous cement, and cannot be considered typical, as most aluminous cements are high in iron. As was pointed out by Bates, there is a wider range in composition than would be found in a similar group of portland cements from various countries. This is true even of the $\mathrm{CaO}$ and $\mathrm{Al}_{2} \mathrm{O}_{3}$ content, although the iron oxides and $\mathrm{SiO}_{2}$ show much greater variability. The ratio of ferric to ferrous iron varies widely, reflecting differences in the furnace atmosphere during manufacture. Titania, derived from the bauxite, usually is present to the extent of about 2 percent. Sulfur present as sulfide was not separately determined, but was known to be present in some of the cements. Alkalies were not determined, but in general, the alkali content of the aluminous cements is much lower than that of portland cements. Many aluminous cements show a gain in weight on ignition, probably because of oxidation of ferrous iron.
The wide variation in composition was accompanied by pronounced differences in the appearance of the clinkers. (The term clinker is here applied to the unground product of the furnace, even though in most cases it had been completely fused.) The clinker of cement 3 , which had not been fused, was of a light-brown color. The absence of FeO clearly indicates that this clinker was burned under oxidizing conditions. Clinker 1, which had been fused in a rotary kiln, showed evidence of having been quenched in water. The centers of the pieces were dark, but the surface layers were reddish brown, indicating oxidation during cooling. Clinkers 2 and 4 were almost black and apparently had been cooled in molds. In both cases, most of the iron is in the ferrous state. Clinkers were not available for cements 5 to 8 .

Although the cements listed in table 1 were produced about 1928-29, rather early after the advent of aluminous cements, they are not essentially different from those recently reported on by Parker [9].

\subsection{Compound Composition}

Although the aluminous cements may properly be classified as calcium aluminate cements, nevertheless the commercial products are decidedly different in composition from the simple anhydrous calcium aluminates or mixtures thereof. In a discussion of the compound composition, it is convenient first to consider the aluminous cements in relation to the

TABLE 1. Chemical analysis and calculated compound composition of aluminous cements

\begin{tabular}{|c|c|c|c|c|c|c|c|c|c|c|}
\hline $\begin{array}{l}\text { Cement No } \\
\text { Designation }\end{array}$ & $\begin{array}{c}1 \\
\text { American } \\
\mathrm{N}-12-\mathrm{B}\end{array}$ & $\begin{array}{c}\stackrel{2}{\text { Italian }} \\
\text { IT-1 }\end{array}$ & $\begin{array}{c}3 \\
\text { Hungar- } \\
\text { HN-1 }\end{array}$ & \multicolumn{2}{|c|}{$\begin{array}{c}4 \\
\text { Swedish } \\
\text { SW-1 }\end{array}$} & $\begin{array}{c}5 \\
\text { French } \\
\text { F-100 }\end{array}$ & \multicolumn{2}{|c|}{$\begin{array}{c}6 \\
\text { English } \\
\text { CE-1 }\end{array}$} & $\begin{array}{c}7 \\
\text { French } \\
\text { (white) } \\
\text { CF-3 }\end{array}$ & $\begin{array}{c}\stackrel{8}{\text { French }} \\
\text { CF-1 }\end{array}$ \\
\hline \multicolumn{11}{|c|}{ OXIDE ANALYSIS } \\
\hline & & & & Total & $\begin{array}{l}\text { Soluble } \\
\text { portion }\end{array}$ & & Total & $\begin{array}{l}\text { Soluble } \\
\text { portion }\end{array}$ & & \\
\hline Insoluble s.. & 2.5 & 4.2 & 3,4 & 3.0 & $\ldots$ & 2.8 & 4.1 & $\ldots$ & 8.6 & 3.1 \\
\hline Loss on ignition & Gain & 0.3 & 0.7 & Gain & & Gain & Gain & & $\begin{array}{l}0.0 \\
1.0\end{array}$ & Gain \\
\hline $\mathrm{CaO}$ & 38.8 & 38.3 & 38.1 & 42,2 & 41.3 & 41.2 & 39.6 & 39.1 & 33. 6 & 42.8 \\
\hline $\mathrm{Al}_{2} \mathrm{O}_{3} \ldots$ & 38.1 & 36.4 & 41.7 & 39.4 & 38.4 & 39.6 & 38.1 & 36.6 & 61.9 & 37.8 \\
\hline $\mathrm{Fe}_{2} \mathrm{O}_{3--}$ & 13.5 & 5.8 & 9.8 & 0.9 & 0.9 & 1.3 & 5.4 & 4.2 & 0.1 & 1. 4 \\
\hline $\mathrm{FeO}$ & 2.0 & 10.3 & 0.0 & 4.1 & 3.9 & 6.0 & 7.2 & 6.0 & .1 & 5.5 \\
\hline $\mathrm{SiO}_{2--}$ & 3. 6 & 5.5 & 6. 0 & 10.0 & 8.7 & 8.1 & 6.7 & 5.3 & 3.0 & 8.5 \\
\hline $\mathrm{MgO}^{-}$ & 1.0 & 0.3 & 1. 1 & 0.6 & 0.6 & 0.6 & 0.1 & 0.1 & 0.2 & 0.4 \\
\hline $\mathrm{TiO}_{2-}$ & 2.0 & 2.0 & 1.5 & 1.7 & 1.1 & 2.0 & 1.8 & .5 & b Trace & 1.8 \\
\hline $\mathrm{Mn}_{2} \mathrm{O}_{3}$ & 0.2 & 0.1 & 0.1 & 0.1 & 0.1 & 0.1 & 0.1 & .1 & 0.1 & 0.1 \\
\hline Total S as $\mathrm{SO}_{3} \ldots$ & .6 & .4 & .9 & .8 & $\ldots$ & .8 & .5 & $\ldots$ & .2 & .9 \\
\hline $\mathrm{P}_{2} \mathrm{O}_{5} \ldots \ldots$ & b Trace & b Trace & b Trace & b Trace & $\cdots$ & b Trace & b Trace & $\ldots$ & b Trace & b Trace \\
\hline Total & 99.8 & 99.4 & 100.1 & 99.8 & -..- & 99.7 & 99.5 &.-- & 100.2 & 99.2 \\
\hline \multicolumn{11}{|c|}{ CALCULATED COMPOUND COMPOSITION } \\
\hline $\mathrm{C}_{6} \mathrm{AF}_{2-}$ & 32.6 & 3.8 & 23.5 & $-\ldots$ & & 3.0 & $\ldots$ & & -... & \\
\hline $\mathrm{C}_{6} \mathrm{~A}_{2} \mathrm{~F}$ & $\cdots$ & -7 & $-\ldots$ & - n & 4.9 & -... & -... & 18.9 & - n & 6.3 \\
\hline $\mathrm{C}_{6} \mathrm{~A}_{4} \mathrm{~F}^{\prime \prime} \mathrm{S}_{-}$ & 45.4 & $\begin{array}{r}7.1 \\
75.3\end{array}$ & 11.0 & $\cdots$ & 60.4 & $84 . \overline{1}$ & -..- & 54.3 & $\ldots$ & 73.5 \\
\hline $\mathrm{CA}$ & 18. 7 & 4.1 & 37.6 & - n & 10.9 & -... &..-- & 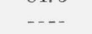 & $65 . \overline{4}$ & $\ldots$ \\
\hline $\begin{array}{l}\mathrm{CA}_{2} \\
\mathrm{C}_{12} \mathrm{~A}_{7}\end{array}$ & $-\cdots$ & $-\cdots$ & 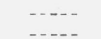 & $\cdots$ & 3.6 & - n & 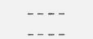 & $\overline{11.7}$ & 19.7 & -5.8 \\
\hline $\mathrm{C}_{2} \mathrm{~A}$ & 2.7 & $-\ldots$ & 24.4 & $\ldots$ & 0.0 & $-\cdots$ & $\ldots$ & 11.1 & 13.4 & \\
\hline $\mathrm{C}_{2} \mathrm{~S}_{\ldots} \ldots \ldots$ & 0.2 & 5. 3 & $\ldots$ & 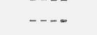 & $15 . \overline{5}$ & 11.5 & $\ldots$ & 5.5 & -.... & 13.8 \\
\hline $\begin{array}{l}\mathrm{FeO} \\
\text { Insoluble } \mathrm{d}\end{array}$ & - n & $\begin{array}{r}4.6 \\
----\end{array}$ & - & $\cdots$ & 4.0 & 0.2 & $-\cdots$ & $\begin{array}{l}1.6 \\
7.2\end{array}$ & $\cdots$ & ... \\
\hline & & & & & & & & & & \\
\hline
\end{tabular}

a According to Federal Specification for portland cement.

b Trace, less than 0.1 percent.

c $\mathrm{Y}_{6} \mathrm{~A}_{4} \mathrm{MS} ; 0.5$ percent of $\mathrm{MgO}$ remains in excess

d A ccording to Parker's procedure 31 
system $\mathrm{CaO}-\mathrm{Al}_{2} \mathrm{O}_{3}-\mathrm{SiO}_{2}$, ignoring for the moment the other components. Compositions ${ }^{2,}{ }^{3}$ representative of the aluminous cements lie in the areas $\mathrm{CA}-\mathrm{C}_{2} \mathrm{~S}-\mathrm{C}_{12} \mathrm{~A}_{7}, \mathrm{CA}-\mathrm{C}_{2} \mathrm{~S}-\mathrm{C}_{2} \mathrm{AS}$, and $\mathrm{CA}-\mathrm{C}_{2} \mathrm{AS}-\mathrm{CA}_{2}$. The two less-basic aluminates, $\mathrm{CA}$ and $\mathrm{CA}_{2}$, have excellent cementitious properties, whereas $\mathrm{C}_{12} \mathrm{~A}_{7}$ sets rapidly and has poor cementitious properties. The silicate $\mathrm{C}_{2} \mathrm{~S}$ is very slow in developing strength, whereas $\mathrm{C}_{2} \mathrm{AS}$ (gehlenite) is practically inert. As Lea and Desch [1] have pointed out, any change that tends to increase the content of $\mathrm{C}_{2} \mathrm{AS}$ in a cement at the expense of $\mathrm{C}_{2} \mathrm{~S}$ and $\mathrm{CA}$, or of $\mathrm{C}_{12} \mathrm{~A}_{7}$ in place of $\mathrm{CA}$, or of the silicate compounds in place of the aluminates, may be expected to be detrimental to strength. They were careful, however, to point out that this argument could not be pursued further, as at that time there were no data available on the quaternary system $\mathrm{CaO}-\mathrm{Al}_{2} \mathrm{O}_{3}-\mathrm{SiO}_{2}-\mathrm{Fe}_{2} \mathrm{O}_{3}$ in the neighborhood of aluminous-cement compositions, and that predictions could not be made as to how changes in composition will affect the manner and order in which the various compounds crystallize from the melt. They also pointed out that the nature of the compounds formed will be affected by changes in the proportion of the iron present in the ferrous and ferric conditions. Because of the importance of the effect of ferrous and ferric oxide on the composition of aluminous cements, an extensive investigation on this subject was undertaken at the Building Research Station of Great Britain. The results of these studies [9] have greatly increased our knowledge of these cements.

Prior to that investigation, considerable information had been obtained by earlier investigators on the mineralogical content of commercial aluminous cements and comparable laboratory preparations. Extensive reports on the subject were given by Sundius [10] and Tavasci [11] at the Symposium on the Chemistry of Cements in Stockbolm in 1938 and by Parker [9] at the Symposium in London in 1952. Among the constituents identified by the earlier workers were $\mathrm{CA} ; \mathrm{C}_{2} \mathrm{AS}$ (geblenite); glass seen in thin section (sometimes almost black and nontransparent, but in other clinkers ligbter in color, often with a dark opaque constituent dispersed with it); a brown constituent thought to be $\mathrm{C}_{4} \mathrm{AF}$; and a brownish anistropic material showing pleochroism and classified as "unstable $\mathrm{C}_{5} \mathrm{~A}_{3}$." It bas been suggested that the dark opaque material in the glass may be magnetite, $\mathrm{Fe}_{3} \mathrm{O}_{4}$. Stable $\mathrm{C}_{5} \mathrm{~A}_{3}$, with the indices raised, possibly by solid solution, bas also been reported. Solacolu [12] found monocalcium ferrite, $\mathrm{CaO} \cdot \mathrm{Fe}_{2} \mathrm{O}_{3}$, in aluminous cements poorer in $\mathrm{CaO}$, but absent in others.

Sundius [10] in particular drew attention to the presence of a glass containing wustite $(\mathrm{FeO})$, and to the probability that the mineral previously identified as unstable $\mathrm{C}_{5} \mathrm{~A}_{3}$ contained $\mathrm{FeO}, \mathrm{SiO}_{2}$, and perhaps

\footnotetext{
${ }^{2}$ In the interest of brevity, the short-hand designations commonly adopted for the various oxides will be used interchangeably with the conventional formulas in this paper: $\mathrm{C}=\mathrm{CaO}, \mathrm{A}=\mathrm{Al}_{2} \mathrm{O}_{3}, \mathrm{~S}=\mathrm{SiO}_{2}, \mathrm{~F}=\mathrm{Fe}_{2} \mathrm{O}_{3}, \mathrm{~F}^{\prime \prime}=\mathrm{FeO}, \mathrm{M}=\mathrm{MgO}$, in this paper: $\mathrm{C}=\mathrm{CaO}$
$\mathrm{T}=\mathrm{TiO}$

3 The compounds earlier designated $\mathrm{C}_{5} \mathrm{~A}_{3}$ and $\mathrm{C}_{3} \mathrm{~A}_{5}$ are now generally believed to be $\mathrm{C}_{12} \mathrm{~A}_{7}$ and $\mathrm{CA}_{2}$, respectively. The newer formulas will be used in this paper, except in reference to earlier works.
}

$\mathrm{TiO}_{2}$, as well as $\mathrm{CaO}$ and $\mathrm{Al}_{2} \mathrm{O}_{3}$. He also suggested the probable presence of $\mathrm{FeO}$ and $\mathrm{Fe}_{2} \mathrm{O}_{3}$ in any gehlenite mineral that occurred. In addition, he identified the presence of perovskite $\left(\mathrm{CaO} \cdot \mathrm{TiO}_{2}\right)$, a ferrite, and iron sulfide, FeS. Sundius pointed out that when dicalcium silicate is present in cement clinker it generally forms ill-defined grains easily overlooked and recognizable chiefly through their high refraction and rather high double refraction.

Tavasci [11], by means of microscopic examination of polished surfaces by reflected light, obtained results in substantial agreement with the findings of Sundius except in the identification of the ferrites. He suspected the presence of more acidic aluminoferrites than those in the $\mathrm{C}_{4} \mathrm{AF}-\mathrm{C}_{2} \mathrm{~F}$ series of solid solutions.

The very important investigation recently reported by Parker [9] was concerned mainly with: (1) The problem of the composition of the mineral known as unstable $\mathrm{C}_{5} \mathrm{~A}_{3}$, (2) the composition of the ferrites (compounds containing $\mathrm{Fe}_{2} \mathrm{O}_{3}$ ), and (3) a method of calculating the compound composition of aluminous cements.

\section{a. Unstable $5 \mathrm{CaO} \cdot 3 \mathrm{Al}_{2} \mathrm{O}_{3}$}

One of the minerals commonly occurring in aluminous cements has been tentatively identified beretofore as the unstable $5 \mathrm{CaO} \cdot 3 \mathrm{Al}_{2} \mathrm{O}_{3}$ reported by Rankin and Wright [13] in the system $\mathrm{CaO}-\mathrm{Al}_{2} \mathrm{O}_{3}$. Parker showed that the cement constituent is more complex, probably having the composition $6 \mathrm{CaO} \cdot 4 \mathrm{Al}_{2} \mathrm{O}_{3} \cdot \mathrm{FeO} \cdot \mathrm{SiO}_{2}$, with some $\mathrm{MgO}$ replacing FeO. He has proposed the following list of assemblages containing $\mathrm{FeO}$ that might pertain to aluminous cement:

$$
\begin{aligned}
& \mathrm{CA}-\mathrm{C}_{6} \mathrm{~A}_{4} \mathrm{~F}^{\prime \prime} \mathrm{S}_{-} \mathrm{C}_{12} \mathrm{~A}_{7}-\mathrm{C}_{2} \mathrm{~S} \\
& \mathrm{CA}-\mathrm{C}_{6} \mathrm{~A}_{4} \mathrm{~F}^{\prime \prime} \mathrm{S}-\mathrm{C}_{2} \mathrm{~S}-\mathrm{C}_{2} \mathrm{AS} \\
& \mathrm{CA}-\mathrm{C}_{6} \mathrm{~A}_{4} \mathrm{~F}^{\prime \prime} \mathrm{S}-\mathrm{C}_{12} \mathrm{~A}_{7}-\mathrm{FeO} \\
& \mathrm{C}_{6} \mathrm{~A}_{4} \mathrm{~F}^{\prime \prime} \mathrm{S}-\mathrm{C}_{12} \mathrm{~A}_{7}-\mathrm{C}_{2} \mathrm{~S}-\mathrm{FeO} \\
& \mathrm{CA}-\mathrm{C}_{6} \mathrm{~A}_{4} \mathrm{~F}^{\prime \prime} \mathrm{S}-\mathrm{C}_{2} \mathrm{~A}-\mathrm{S}-\mathrm{FeO} .
\end{aligned}
$$

Those containing $\mathrm{FeO}$ as a separate phase would give a theoretical basis for Sundius' observations on the presence of glasses containing inclusions of wustite.

\section{b. Ferrites}

As pointed out by Parker, knowledge of the phase equilibria of the ferrites in aluminous cement is still incomplete. In a study of the area $\mathrm{CaO}-\mathrm{C}_{4} \mathrm{AF}-\mathrm{CA}$, McMurdie [14] found that the aluminates, $\mathrm{C}_{3} \mathrm{~A}, \mathrm{C}_{12^{-}}$ $\mathrm{A}_{7}$, and $\mathrm{CA}$, take up to 2.5 percent of $\mathrm{Fe}_{2} \mathrm{O}_{3}$ into solid solution. Swayze [15] showed that the solidsolution series between $\mathrm{C}_{2} \mathrm{~F}$ and a hypothetical $\mathrm{C}_{2} \mathrm{~A}$ extends as far as $\mathrm{C}_{6} \mathrm{~A}_{2} \mathrm{~F}$ in the $\mathrm{C}_{2} \mathrm{~A}$-direction. From these and other earlier data, together with data from his own investigations, Parker concluded that mixes in the aluminous cement region may crystallize in one of the following assemblages:

\section{$\mathrm{C}_{12} \mathrm{~A}_{7}(\mathrm{ss})$ and $\mathrm{CA}(\mathrm{ss})$}

$\mathrm{CA}(\mathrm{ss}), \mathrm{C}_{12} \mathrm{~A}_{7}(\mathrm{ss})$, and $\mathrm{C}_{6} \mathrm{~A}_{2} \mathrm{~F}$

$\mathrm{CA}(\mathrm{ss})$ and a solid solution on the line $\mathrm{C}_{6} \mathrm{~A}_{2} \mathrm{~F}-\mathrm{C}_{2} \mathrm{~F}$

$\mathrm{CA}(\mathrm{ss}), \mathrm{CF}(\mathrm{ss})$, and a solid solution on the line $\mathrm{C}_{6} \mathrm{~A}_{2} \mathrm{~F}-\mathrm{C}_{2} \mathrm{~F}$. 
Parker also stated that evidence from the examination of microscopic sections shows that the composition of the ferrite can proceed as far as a point corresponding to $\mathrm{C}_{6} \mathrm{AF}_{2}$, although the equilibrium in this case is not in the system $\mathrm{CaO}-\mathrm{Al}_{2} \mathrm{O}_{3}-\mathrm{Fe}_{2} \mathrm{O}_{3}$ but on aluminous-cement compositions having additional oxides.

Parker applied a technique of microreflectivity measurements on polished thin sections and found indications that cements whose aluminate constituents are solely unstable $\mathrm{C}_{5} \mathrm{~A}_{3}$, or the latter with stable $\mathrm{C}_{12} \mathrm{~A}_{7}$, are in equilibrium with the ferrite $\mathrm{C}_{6} \mathrm{~A}_{2} \mathrm{~F}$; cements containing unstable $\mathrm{C}_{5} \mathrm{~A}_{3}$ with a little $\mathrm{CA}$ are in equilibrium with a solid solution lying between $\mathrm{C}_{6} \mathrm{~A}_{2} \mathrm{~F}$ and $\mathrm{C}_{4} \mathrm{AF}$; and those containing mainly $\mathrm{CA}$ with a ferrite solution between $\mathrm{C}_{4} \mathrm{AF}$ and $\mathrm{C}_{6} \mathrm{AF}_{2}$. Parker pointed out the need for further detailed study within the system $\mathrm{CaO}-\mathrm{Al}_{2} \mathrm{O}_{3}-\mathrm{Fe}_{2} \mathrm{O}_{3}$ and a series of studies of the equilibrium of the four component system $\mathrm{CaO}-\mathrm{Al}_{2} \mathrm{O}_{3}-\mathrm{Fe}_{2} \mathrm{O}_{3}-\mathrm{FeO}$.

\section{c. Calculation of Compound Composition}

Parker [9] devised methods for calculating the compound composition of aluminous cements from the oxide analysis, making use of the information derived from the phase and mineralogical studies described in the previous sections. For a number of reasons, discussed in Parker's paper, the solutions are only approximate.

The compound compositions of the eight aluminous cements listed in table 1 are given in the lower part of the table. The methods of Parker were followed, with certain unavoidable departures. Parker's procedure requires a separate analysis of the residue left undissolved after a specified acid treatment. Most of the samples of the cements listed in table 1 had been discarded before Parker's report appeared, hence it was necessary to base the compound computation on the total analysis. Cements 4 and 6 were still available; they were therefore reanalyzed, and the calculations were based on the analysis of the soluble portion. Further modifications were required in the case of cement 7 because its composition is outside the range in which Parker's methods apply.

Granting that at best the calculations give only approximate solutions, nevertheless, the tabulations given in table 1 show that the compound compositions of the different cements vary markedly from one another. Parker likewise showed for the eight cements on which he reported, that there was wide variation in the calculated compound compositions.

\section{Mechanism of the Reaction of Water With Aluminous Cements}

\subsection{General Procedure}

The procedure followed was to shake the anhydrous cement with distilled water in the proportion of $50 \mathrm{~g}$ of solid to 1 liter of water for a given time and then to filter the mixture rapidly through a Buchner funnel. Samples of these filtrates were taken at once for chemical analyses and for $p \mathrm{H}$ determinations. The filtered solutions were then set aside in well-stoppered flasks for further observations. Part of the lime and alumina precipitated from the clear solutions, on standing, in changing from an unstable condition to one more nearly approaching equilibrium. At a later date the resulting mixtures were filtered. Samples of these filtrates were also taken for chemical analyses and for $p \mathrm{H}$ determinations. The precipitates were washed with alcohol and ether and dried in a desiccator containing anhydrous calcium chloride. The dried material was examined with a petrographic microscope, and in many instances was analyzed chemically for lime, alumina, and water (loss on ignition). In all cases the molar ratio $\mathrm{CaO} / \mathrm{Al}_{2} \mathrm{O}_{3}$ in the precipitate was calculated from the difference between the composition of the unstable solution before and after precipitation.

In general, this is the procedure followed in the earlier study of the reaction of water on calcium aluminates and a high-alumina cement [4]. In that investigation the mixtures that precipitated from the clear unstable aluminate solutions were allowed to stand for 2 weeks before filtering. In the present study they were kept for 4 to 5 months to approach more nearly a steady state.

\subsection{Reaction With Anhydrous Calcium Aluminates}

The mechanism of the reaction of water with the anhydrous calcium aluminates was the subject of an earlier paper [4]. The pertinent findings are summarized here to facilitate comparison with the data newly presented. Figure 1 shows the compositions of solutions resulting from the action of water on three anhydrous aluminate compositions: $\mathrm{CA}, \mathrm{C}_{3} \mathrm{~A}_{5}$, and $\mathrm{C}_{5} \mathrm{~A}_{3}$. (The older formulas are retained here, because they represent the actual proportions of the oxides present.) The figures adjacent to the plotted points indicate the time of contact between liquid and solid phases. Tricalcium aluminate, $\mathrm{C}_{3} \mathrm{~A}$, is not included because its reaction is too rapid to be followed in this way.

Despite the range in $\mathrm{CaO} / \mathrm{Al}_{2} \mathrm{O}_{3}$ ratio, all three aluminates reacted in much the same manner. The solutions approximated the composition of monocalcium aluminate, but were slightly more basic. The concentration reached a maximum in about 30 min $\left(2 \mathrm{hr}\right.$ in the case of $\left.\mathrm{C}_{5} \mathrm{~A}_{3}\right)$, then decreased as solid phases separated out. The fall in concentration became very rapid between 5 and $6 \mathrm{hr}$ for CA, and between 2 and $3 \mathrm{hr}$ for the other two aluminates. This fall was accompanied by a rise in $p H$. The period of rapid precipitation ended when the concentration was approximately $0.5 \mathrm{~g}$ of $\mathrm{CaO}$ and $0.6 \mathrm{~g}$ of $\mathrm{Al}_{2} \mathrm{O}_{3}$ per liter (point $\mathrm{A}$ in fig. 1). From this point the precipitation was very slow, and the curve $\mathrm{AB}$ becomes almost vertical (that is, the $\mathrm{CaO}$ concentration remained practically constant as $\mathrm{Al}_{2} \mathrm{O}_{3}$ is removed from solution). The average concentration at $\mathrm{B}$ is $0.46 \mathrm{~g}$ of $\mathrm{CaO}$ and $0.16 \mathrm{~g} \mathrm{Al} \mathrm{Al}_{2} \mathrm{O}_{3}$ per liter. The $p \mathrm{H}$ continued to rise during the latter stage, and became 11.7 to 11.8 when $B$ was reached.

When the clear filtrates obtained at the earlier periods were allowed to stand, precipitation started 


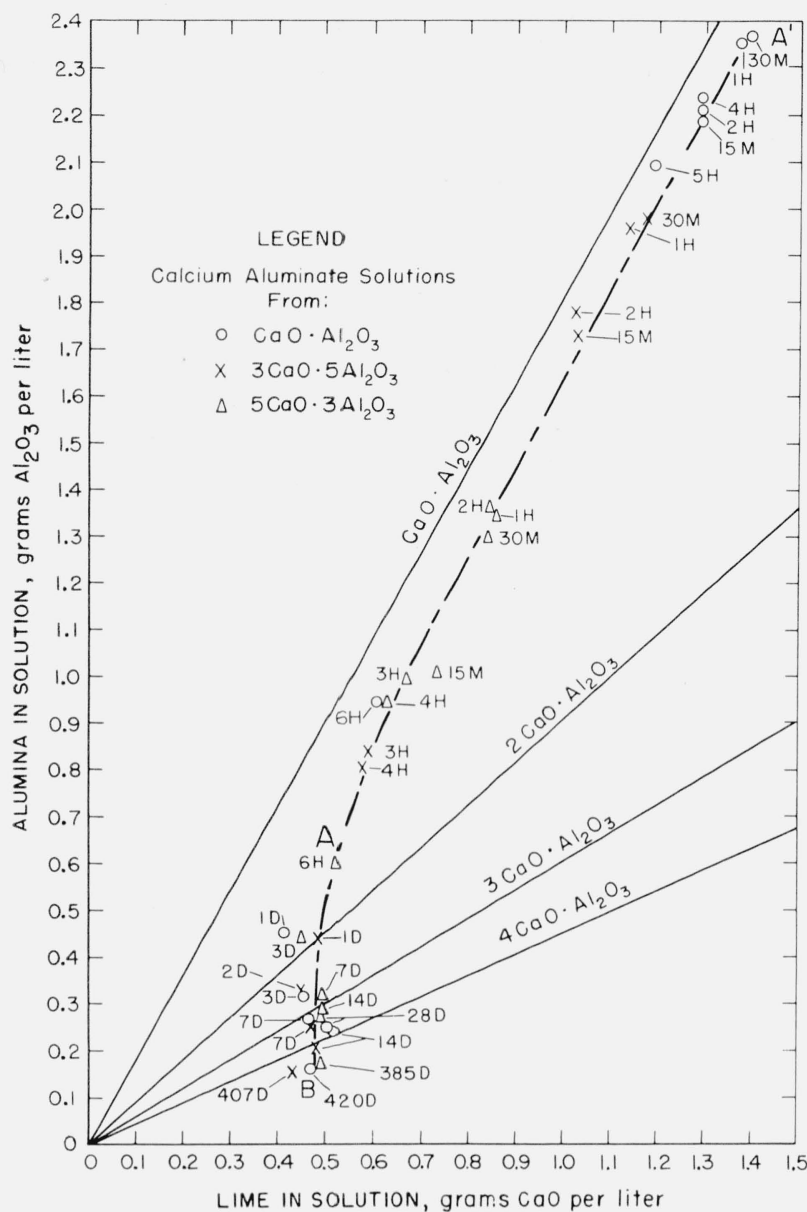

Figure 1. Compositions of solutions resulting from the reaction of water with anhydrous calcium aluminates.

Notations adjacent to plotted points indicate time in minutes, hours, or days.

within 2 to $3 \mathrm{hr}$, and followed the same path along $\mathrm{A}^{\prime} \mathrm{B}$.

Chemical analysis of the material precipitated in the approach from an unstable condition to one more nearly approximating a steady state (B, fig. 1) indicated a molar ratio of $\mathrm{CaO} / \mathrm{Al}_{2} \mathrm{O}_{3}$ less than 1.0. Microscopic examination showed that the samples were composed almost wholly of two phases:

A. A crystalline phase in flat, hexagonal plates with the refractive indices of the better developed crystals as follows: $\omega=1.535 \pm 0.004, \quad \epsilon=1.515$ \pm 0.005 ; optical character uniaxial negative. There were spherulites consisting of radiating aggregates of these crystals. The refractive indices were somewhat variable. At the time, this was believed to be a hexagonal tricalcium aluminate hydrate, but later work [6] has shown that it was more probably dicalcium aluminate hydrate.

B. Amorphous material, apparently colloidal aggregates, often in spheroidal form in irregular clumps, also in thin flakes, as if broken away from the containing vessel. Often this film of material was imbedded in and partially covered the clusters of hexagonal plates described under A. This indicates that the films were formed subsequent to the spherulites of the hydrated calcium aluminate. It was difficult to obtain the refractive index of the amorphous material. The average index was about 1.48 , but in some instances it was somewhat higherin a few cases nearly 1.55. Often the refractive index of the outside of the pellets and flakes was greater than that of the inside portion. The amorphous material is believed to be hydrated alumina.

There were, in addition to the above, minor quantities of two other phases:

C. Isotropic, isometric crystals with an index of refraction very close to 1.605 . Later investigations have shown that this was $\mathrm{C}_{3} \mathrm{AH}$. This phase was found in only a few of the precipitates, and then in small amounts.

D. Calcite. This occurred in aggregates of very minute crystals seldom exceeding $5 \mu$ in greatest dimension. It occurred in very small amounts, and not in all samples. The small quantity of calcite found in the precipitated material undoubtedly resulted from slow carbonation after the mixtures were filtered, as no carbonate was found directly upon filtering.

From these experiments it would appear that the reactions between woter and monocalcium aluminate, as well as the 5:3 calcium aluminate and the $3: 5$ calcium aluminate, are in part related to the precipitation of hydrated alumina and a crystalline hydrated calcium aluminate (probably $2 \mathrm{CaO} \cdot \mathrm{Al}_{2} \mathrm{O}_{3}$-$8 \mathrm{H}_{2} \mathrm{O}$ ) from metastable and supersaturated monocalcium aluminate solutions.

Other investigators have verified these conclusions and added to our knowledge of the mechanism. Assarsson [16] showed that the various calcium aluminates dissolve in water at first without hydrolysis, so that the ratio of $\mathrm{CaO}$ to $\mathrm{Al}_{2} \mathrm{O}_{3}$ in solution is the same as that in the original material. However, the composition of the solution soon changes because pure calcium aluminate solution can contain lime and alumina only in a ratio about $1 \cdot 1: 1$. In the case of anhydrous $\mathrm{CA}$, the original $\mathrm{C} / \mathrm{A}$ ratio in solution is $1: 1$, but this increases slightly as hydrated $\mathrm{Al}_{2} \mathrm{O}_{3}$ is separated by hydrolysis, and the concentration continues to increase in the $\mathrm{C} / \mathrm{A}$ ratio about 1:1. The same is true of anhydrous $\mathrm{C}_{3} \mathrm{~A}_{5}$, except that the $\mathrm{Al}_{2} \mathrm{O}_{3}$ separating is correspondingly greater. With $\mathrm{C}_{5} \mathrm{~A}_{3}$ the same process occurs, except that here the hydrate $2 \mathrm{CaO} \cdot \mathrm{Al}_{2} \mathrm{O}_{3} \cdot 8 \mathrm{H}_{2} \mathrm{O}$ is formed simultaneously with a smaller amount of hydrated $\mathrm{Al}_{2} \mathrm{O}_{3}$, and the maximum concentration attained is not so high. This is reflected in the more rapid set and the lower strength of $\mathrm{C}_{5} \mathrm{~A}_{3}$ pastes as compared with the less basic aluminates.

The observation of Assarsson about the initial solubility of the calcium aluminates was confirmed by Forsen [17] and Hedin [18] by shaking small amounts $(0.2 \mathrm{~g})$ of the calcium aluminates in a large excess (1 liter) of water at $20^{\circ} \mathrm{C}$.

\subsection{Reactions With Aluminous Cements}

Data relating to the composition and $p \mathrm{H}$ of solutions obtained from the eight aluminous cements are given in table 2. The data in the columns designated "A" refer to the clear filtrates immediately 
TABLE 2. Composition and $p \mathrm{H}$ of aluminate solutions from calcium aluminate cements

\begin{tabular}{|c|c|c|c|c|c|c|c|c|c|c|c|c|}
\hline \multirow{2}{*}{ No. } & \multirow{2}{*}{$\begin{array}{l}\text { Time of con- } \\
\text { tact of } \\
\text { cement } \\
\text { with water } \\
\text { before } \\
\text { filtering }\end{array}$} & \multicolumn{2}{|c|}{$\begin{array}{l}\text { Total alumina in } \\
\mathrm{sol} \text { tion, g of } \\
\mathrm{Al}_{2} \mathrm{O}_{3} \text { per liter }\end{array}$} & \multicolumn{2}{|c|}{$\begin{array}{l}\text { Total lime in solu- } \\
\text { tion, } \mathrm{g} \text { of } \mathrm{CaO} \text { per } \\
\text { liter }\end{array}$} & \multicolumn{2}{|c|}{$\begin{array}{l}\text { Molar ratio, } \mathrm{CaO} / \\
\mathrm{Al}_{2} \mathrm{O}_{3} \text { in solution }\end{array}$} & \multicolumn{2}{|c|}{$\begin{array}{l}\text { Lime in solutinn in } \\
\text { excess of } \mathrm{CaO} \text {. } \\
\mathrm{Al}_{2} \mathrm{O}_{3}, \mathrm{~g} \text { of } \mathrm{CaO} \\
\text { per liter }\end{array}$} & \multicolumn{2}{|c|}{$p \mathrm{H}$ of solutions } & \multirow{2}{*}{$\begin{array}{c}\text { Molar } \\
\text { ratio, } \\
\mathrm{CaO} / \mathrm{Al}_{2} \mathrm{O}_{3} \\
\text { in } \\
\text { precipitate }\end{array}$} \\
\hline & & $\begin{array}{c}\text { A } \\
\text { Directly } \\
\text { upon } \\
\text { filtering }\end{array}$ & $\begin{array}{c}\text { B } \\
\text { At equi- } \\
\text { librium }\end{array}$ & $\begin{array}{c}\text { A } \\
\text { Directly } \\
\text { upon } \\
\text { filtering }\end{array}$ & $\begin{array}{c}\text { B } \\
\text { At equi- } \\
\text { librium }\end{array}$ & $\begin{array}{c}\text { A } \\
\text { Directly } \\
\text { upon } \\
\text { filtering }\end{array}$ & $\begin{array}{c}\text { B } \\
\text { At equi- } \\
\text { librium }\end{array}$ & $\begin{array}{c}\text { A } \\
\text { Directly } \\
\text { upon } \\
\text { filtering }\end{array}$ & \begin{tabular}{|}
\multicolumn{1}{c}{ B } \\
At equi- \\
librium
\end{tabular} & $\begin{array}{c}\text { A } \\
\text { Directly } \\
\text { upon } \\
\text { filtering }\end{array}$ & \begin{tabular}{l}
\multicolumn{1}{c}{ B } \\
At equi- \\
librium
\end{tabular} & \\
\hline 1 & 2 & 3 & 4 & 5 & 6 & 7 & 8 & 9 & 10 & 11 & 12 & 13 \\
\hline \multicolumn{13}{|c|}{ CEMENT 1 (AMERTCAN; N-12-B) } \\
\hline $\begin{array}{l}1 \\
2 \\
3 \\
4 \\
5\end{array}$ & $\begin{array}{l}15 \mathrm{~min} \\
30-\min . \\
1 \mathrm{hr} \\
2 \mathrm{hr} \\
4 \mathrm{hr}\end{array}$ & $\begin{array}{l}\text { 1. } 7950 \\
\text { 1. } 7870 \\
1.9140 \\
2.0530 \\
2.0200\end{array}$ & $\begin{array}{l}0.1855 \\
.1830 \\
.1700 \\
.1755 \\
.1855\end{array}$ & $\begin{array}{l}1.1600 \\
1.1430 \\
1.1820 \\
1.2770 \\
1.2380\end{array}$ & $\begin{array}{r}0.4825 \\
.4785 \\
.4625 \\
.4725 \\
.4620\end{array}$ & $\begin{array}{l}1.17 \\
1.15 \\
1.12 \\
1.13 \\
1.11\end{array}$ & $\begin{array}{l}4.72 \\
4.74 \\
4.94 \\
4.90 \\
4.53\end{array}$ & $\begin{array}{r}0.1727 \\
.1601 \\
.1292 \\
.1478 \\
.1270\end{array}$ & $\begin{array}{r}0.3805 \\
.3778 \\
.3690 \\
.3760 \\
.3600\end{array}$ & $\begin{array}{l}\text { 11. } 46 \\
11.42 \\
11.32 \\
11.39 \\
11.32\end{array}$ & $\begin{array}{l}11.79 \\
11.79 \\
11.78 \\
11.79 \\
11.77\end{array}$ & $\begin{array}{l}0.77 \\
.75 \\
.75 \\
.78 \\
.77\end{array}$ \\
\hline $\begin{array}{r}6 \\
7 \\
8 \\
9 \\
10\end{array}$ & $\begin{array}{l}6 \mathrm{hr} \\
8 \mathrm{hr} \\
10 \mathrm{hr} \\
12 \mathrm{hr} \\
1 \text { day }\end{array}$ & $\begin{array}{l}1.8930 \\
1.4100 \\
1.4300 \\
1.0950 \\
0.4000\end{array}$ & $\begin{array}{l}.1720 \\
.2335 \\
.1180 \\
.2510\end{array}$ & $\begin{array}{l}1.1330 \\
0.9100 \\
.8940 \\
.7120 \\
.4670\end{array}$ & $\begin{array}{l}.4605 \\
.4695 \\
.4400 \\
.4500 \\
. . .\end{array}$ & $\begin{array}{l}1.09 \\
1.17 \\
1.14 \\
1.19 \\
2.12\end{array}$ & $\begin{array}{l}4.85 \\
3.65 \\
6.78 \\
3.23 \\
\end{array}$ & $\begin{array}{l}.0918 \\
.1345 \\
.1075 \\
.1098 \\
.2470\end{array}$ & $\begin{array}{r}.3659 \\
.3411 \\
.3751 \\
.3120 \\
-. .--\end{array}$ & $\begin{array}{l}11.13 \\
11.36 \\
11.20 \\
11.25 \\
11.61\end{array}$ & $\begin{array}{l}11.78 \\
11.75 \\
11.79 \\
11.71\end{array}$ & $\begin{array}{l}.71 \\
.68 \\
.63 \\
.56 \\
\end{array}$ \\
\hline 11 & 3 days .... & .2920 & & .4230 & -..--- & 2.57 & ----. & .2624 & -..... & 11.64 & -..-. & 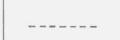 \\
\hline \multicolumn{13}{|c|}{ CEMENT 2 (ITALIAN; IT- 1 ) } \\
\hline $\begin{array}{l}1 \\
2 \\
3 \\
4 \\
5\end{array}$ & $\begin{array}{l}15 \mathrm{~min} \\
30 \mathrm{~min} \\
1 \mathrm{hr} \\
2 \mathrm{hr} \\
4 \mathrm{hr}\end{array}$ & $\begin{array}{l}1.0820 \\
1.1580 \\
1.3440 \\
1.5470 \\
1.7780\end{array}$ & $\begin{array}{l}0.2415 \\
.2145 \\
.1725 \\
.1715 \\
.1685\end{array}$ & $\begin{array}{r}0.7490 \\
.7840 \\
.8850 \\
.9810 \\
1.0750\end{array}$ & $\begin{array}{r}0.4565 \\
.4425 \\
.4830 \\
.4800 \\
.4785\end{array}$ & $\begin{array}{l}1.26 \\
1.21 \\
1.20 \\
1.15 \\
1.09\end{array}$ & $\begin{array}{l}3.43 \\
3.75 \\
5.09 \\
5.09 \\
5.18\end{array}$ & $\begin{array}{r}0.1539 \\
.1471 \\
.1458 \\
.1301 \\
.0971\end{array}$ & $\begin{array}{l}0.3237 \\
.3245 \\
.3381 \\
.3857 \\
.3858\end{array}$ & $\begin{array}{l}\text { 11. } 39 \\
\text { 11. } 37 \\
\text { 11. } 37 \\
\text { 11. } 32 \\
11.09\end{array}$ & $\begin{array}{l}11.72 \\
11.72 \\
11.80 \\
11.80 \\
11.80\end{array}$ & $\begin{array}{l}0.60 \\
.66 \\
.63 \\
.66 \\
.67\end{array}$ \\
\hline $\begin{array}{r}6 \\
7 \\
8 \\
9 \\
10\end{array}$ & $\begin{array}{l}6 \mathrm{hr} \\
8 \mathrm{hr} \\
10 \mathrm{hr} \\
12 \mathrm{hr} \\
1 \mathrm{day}\end{array}$ & $\begin{array}{l}\text { 1. } 7880 \\
1.5820 \\
1.3550 \\
1.0500 \\
0.7080\end{array}$ & $\begin{array}{l}.1715 \\
.2070 \\
.1885 \\
.2685 \\
. . .-\end{array}$ & $\begin{array}{r}1.0660 \\
0.9490 \\
.8220 \\
.7120 \\
.5270\end{array}$ & $\begin{array}{l}.4860 \\
.4975 \\
.4735 \\
.4335 \\
. .-\end{array}$ & $\begin{array}{l}1.08 \\
1.09 \\
1.10 \\
1.23 \\
1.35\end{array}$ & $\begin{array}{l}5.15 \\
4.36 \\
4.57 \\
2.94 \\
2.12\end{array}$ & $\begin{array}{l}.0826 \\
.0789 \\
.0768 \\
.1345 \\
.1376\end{array}$ & $\begin{array}{l}.3917 \\
.3836 \\
.3698 \\
.2858 \\
.2151\end{array}$ & $\begin{array}{l}\text { 11. } 08 \\
\text { 11. } 07 \\
\text { 11. } 06 \\
\text { 11. } 34 \\
\text { 11. } 35\end{array}$ & $\begin{array}{l}11.80 \\
11.80 \\
11.79 \\
11.68 \\
11.56\end{array}$ & $\begin{array}{r}.65 \\
.60 \\
.54 \\
.78 \\
.-.\end{array}$ \\
\hline $\begin{array}{l}11 \\
12 \\
13\end{array}$ & $\begin{array}{l}3 \text { days. } \\
14 \text { days_-- } \\
28 \text { days.--- }\end{array}$ & $\begin{array}{l}.2875 \\
.2210 \\
.1625\end{array}$ & - & $\begin{array}{l}.3915 \\
.3165 \\
.4650\end{array}$ & 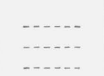 & $\begin{array}{l}2.47 \\
\text { 2. } 60 \\
5.20\end{array}$ & - & $\begin{array}{l}.2334 \\
.1950 \\
.3756\end{array}$ & - & $\begin{array}{l}11.59 \\
11.52 \\
11.79\end{array}$ & - & - \\
\hline \multicolumn{13}{|c|}{ CEMENT 3 (HUNGARIAN; HN-1) } \\
\hline $\begin{array}{l}1 \\
2 \\
3 \\
4 \\
5\end{array}$ & $\begin{array}{l}15 \mathrm{~min} \\
30 \mathrm{~min}- \\
1 \mathrm{hr}- \\
2 \mathrm{hr}_{-} \\
4 \mathrm{hr}\end{array}$ & $\begin{array}{l}0.8730 \\
1.1700 \\
1.1840 \\
1.5080 \\
1.5950\end{array}$ & $\begin{array}{l}0.1700 \\
.1910 \\
.1910 \\
.1805 \\
.1775\end{array}$ & $\begin{array}{r}0.5900 \\
.7610 \\
.7550 \\
.9140 \\
.9920\end{array}$ & $\begin{array}{r}0.3200 \\
.4555 \\
.4665 \\
.4895 \\
.4850\end{array}$ & $\begin{array}{l}1.23 \\
1.18 \\
1.15 \\
1.10 \\
1.13\end{array}$ & $\begin{array}{l}3.42 \\
4.33 \\
4.44 \\
4.93 \\
4.97\end{array}$ & $\begin{array}{l}0.1052 \\
.1175 \\
.1021 \\
.0846 \\
.1147\end{array}$ & $\begin{array}{l}0.2265 \\
.3505 \\
.3615 \\
.3903 \\
.3864\end{array}$ & $\begin{array}{l}11.21 \\
11.26 \\
11.14 \\
11.08 \\
11.25\end{array}$ & $\begin{array}{l}11.58 \\
11.76 \\
11.77 \\
11.80 \\
11.80\end{array}$ & $\begin{array}{l}0.69 \\
.56 \\
.52 \\
.57 \\
.65\end{array}$ \\
\hline $\begin{array}{r}6 \\
7 \\
8 \\
9 \\
10\end{array}$ & $\begin{array}{l}6 \mathrm{hr} \\
8 \mathrm{hr} \\
10 \mathrm{hr} \\
12 \mathrm{hr} \\
1 \text { day }\end{array}$ & $\begin{array}{l}1.8160 \\
1.7450 \\
1.3250 \\
1.1470 \\
0.8310\end{array}$ & $\begin{array}{l}.1800 \\
.1830 \\
.1755 \\
.2115\end{array}$ & $\begin{array}{l}1.1070 \\
1.0820 \\
0.8600 \\
.7660 \\
.6110\end{array}$ & $\begin{array}{l}.4850 \\
.4935 \\
.4630 \\
.4270\end{array}$ & $\begin{array}{l}1.11 \\
1.12 \\
1.18 \\
1.21 \\
1.33\end{array}$ & $\begin{array}{l}4.90 \\
4.90 \\
4.80 \\
3.66 \\
3.06\end{array}$ & $\begin{array}{l}.1082 \\
.1222 \\
.1312 \\
.1351 \\
.1540\end{array}$ & $\begin{array}{l}.3860 \\
.3928 \\
.3667 \\
.3107 \\
.3207\end{array}$ & $\begin{array}{l}11.20 \\
11.28 \\
11.32 \\
11.34 \\
11.41\end{array}$ & $\begin{array}{l}11.80 \\
11.81 \\
11.78 \\
11.71 \\
11.73\end{array}$ & $\begin{array}{l}.68 \\
.68 \\
.63 \\
.66\end{array}$ \\
\hline $\begin{array}{l}11 \\
12 \\
13 \\
14\end{array}$ & $\begin{array}{l}3 \text { days } \\
7 \text { days } \\
14 \text { days--- } \\
28 \text { days }-.-\end{array}$ & $\begin{array}{l}.4020 \\
.2855 \\
.2450 \\
.2035\end{array}$ & & $\begin{array}{l}.4000 \\
.4010 \\
.4385 \\
.3350\end{array}$ & & $\begin{array}{l}1.81 \\
2.54 \\
3.25 \\
3.00\end{array}$ & & $\begin{array}{l}.1789 \\
.2440 \\
.3037 \\
.2231\end{array}$ & & $\begin{array}{l}11.48 \\
11.59 \\
11.70 \\
11.57\end{array}$ & & \\
\hline \multicolumn{13}{|c|}{ CEMENT 4 (SWEDISH; SW-1) } \\
\hline $\begin{array}{l}1 \\
2 \\
3 \\
4 \\
5\end{array}$ & $\begin{array}{l}15 \mathrm{~min} \\
30 \mathrm{~min}-\ldots \\
1 \mathrm{hr} \\
2 \mathrm{hr} \\
4 \mathrm{hr}\end{array}$ & $\begin{array}{l}1.1410 \\
1.3700 \\
1.6430 \\
1.6000 \\
1.7030\end{array}$ & $\begin{array}{l}0.2795 \\
.2000 \\
.1900 \\
.1885 \\
.1910\end{array}$ & $\begin{array}{r}0.8000 \\
.8900 \\
1.0380 \\
1.0070 \\
1.0320\end{array}$ & $\begin{array}{l}0.4500 \\
.4770 \\
.4475 \\
.4565 \\
.4800\end{array}$ & $\begin{array}{l}1.28 \\
1.18 \\
1.15 \\
1.15 \\
1.10\end{array}$ & $\begin{array}{l}2.93 \\
4.34 \\
4.28 \\
4.40 \\
4.56\end{array}$ & $\begin{array}{l}0.1724 \\
.1365 \\
.1343 \\
.1270 \\
.0930\end{array}$ & $\begin{array}{r}0.2963 \\
.3670 \\
.3430 \\
.3528 \\
.3750\end{array}$ & $\begin{array}{l}11.45 \\
11.34 \\
11.33 \\
11.30 \\
11.08\end{array}$ & $\begin{array}{l}11.69 \\
11.78 \\
11.75 \\
11.76 \\
11.78\end{array}$ & $\begin{array}{l}0.74 \\
.64 \\
.74 \\
.71 \\
.66\end{array}$ \\
\hline $\begin{array}{r}6 \\
7 \\
8 \\
9 \\
10\end{array}$ & $\begin{array}{l}6 \mathrm{hr} \\
8 \mathrm{hr}-\ldots \\
10 \mathrm{hr} \\
12 \mathrm{hr} \\
1 \text { day }\end{array}$ & $\begin{array}{l}1.4980 \\
1.4330 \\
1.2500 \\
0.9210 \\
.6900\end{array}$ & $\begin{array}{l}.1935 \\
.1840 \\
.1985 \\
.3025\end{array}$ & $\begin{array}{r}0.9070 \\
.8640 \\
.7650 \\
.6050 \\
.5130\end{array}$ & $\begin{array}{l}.4565 \\
.4830 \\
.4345 \\
.4140\end{array}$ & $\begin{array}{l}1.10 \\
1.10 \\
1.11 \\
1.19 \\
1.35\end{array}$ & $\begin{array}{l}\text { 4. } 29 \\
4.80 \\
\text { 3. } 93 \\
2.49 \\
1.33\end{array}$ & $\begin{array}{l}.0830 \\
.0758 \\
.0755 \\
.0984 \\
.1335\end{array}$ & $\begin{array}{r}.3510 \\
.3818 \\
.3253 \\
.2474 \\
.1245\end{array}$ & $\begin{array}{l}\text { 11. } 07 \\
\text { 11. } 06 \\
11.06 \\
11.11 \\
11.33\end{array}$ & $\begin{array}{l}11.76 \\
11.80 \\
11.73 \\
11.61 \\
11.30\end{array}$ & $\begin{array}{l}.63 \\
.55 \\
.57 \\
.56\end{array}$ \\
\hline $\begin{array}{l}11 \\
12 \\
13 \\
14\end{array}$ & \begin{tabular}{|l|}
3 days_-..-- \\
7 days \\
14 days.--- \\
28 days
\end{tabular} & $\begin{array}{l}.3015 \\
.2050 \\
.2450 \\
.2460\end{array}$ & & $\begin{array}{l}.3450 \\
.3795 \\
.2400 \\
.2000\end{array}$ & & $\begin{array}{l}2.08 \\
3.37 \\
1.78 \\
1.48\end{array}$ & & $\begin{array}{l}.1792 \\
.2667 \\
.1112 \\
.0647\end{array}$ & & $\begin{array}{l}11.48 \\
11.62 \\
11.18 \\
11.05\end{array}$ & & \\
\hline
\end{tabular}


TABLE 2. Composition and $p \mathrm{H}$ of aluminate solutions from calcium aluminate cements - Continued

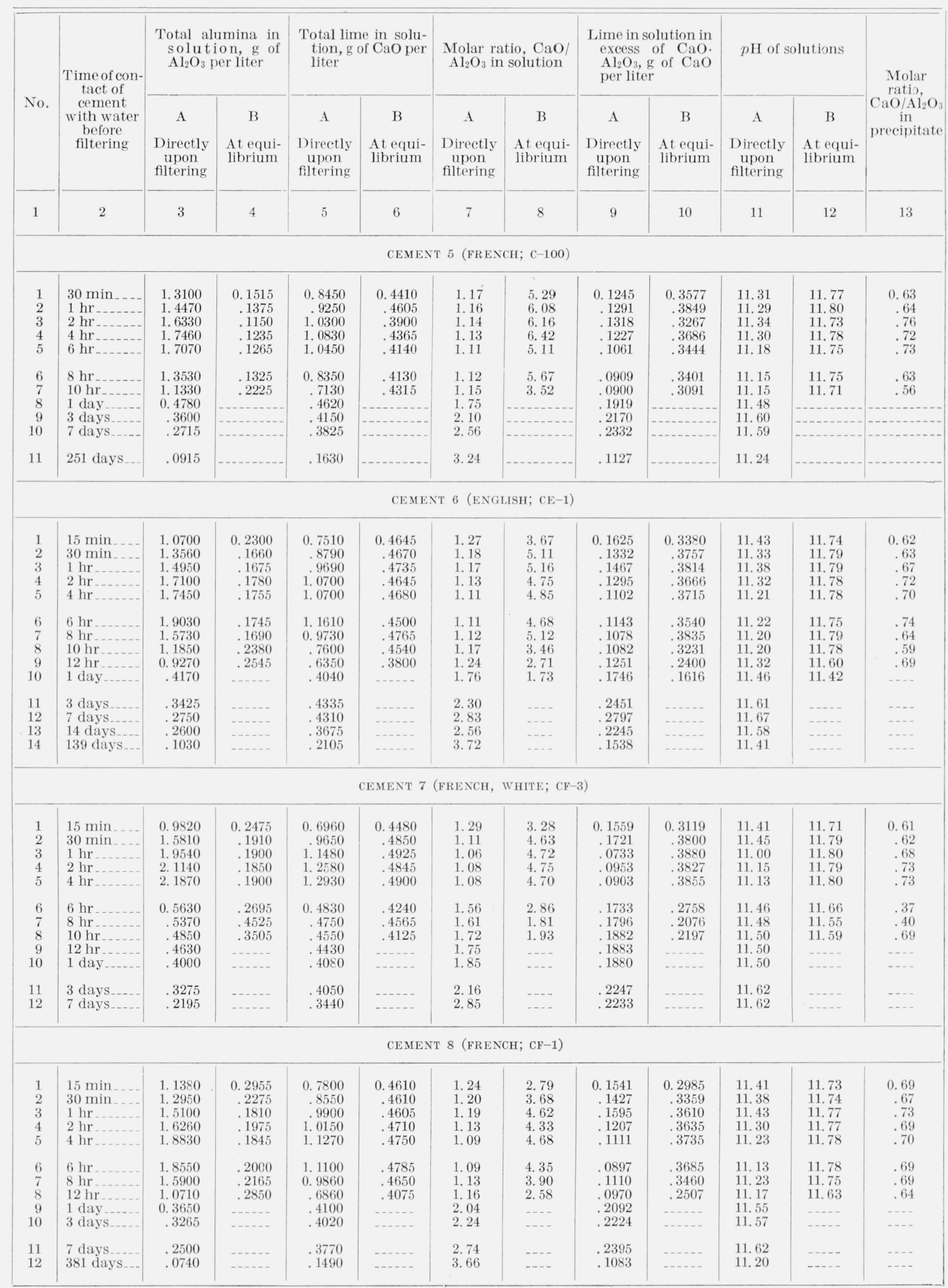


after removal of the cement residue by filtration. Data in columns designated "B" apply to the same filtrates after they had stood for 4 to 5 months. The term "at equilibrium" is here used for brevity, but a true equilibrium does not actually exist at this stage. It is rather a prolonged metastable or steady state, the significance of which will be discussed later.

From the data of columns 3 and 5 it is seen that the reaction of water on all of the aluminous cements progressed fairly rapidly. The quantity of both alumina and lime dissolved by the water attained a maximum in 2 to $6 \mathrm{hr}$ and then gradually decreased. Further shaking of the mixture resulted in a rapid decrease for the white cement (No. 7) after the maximum at $4 \mathrm{hr}$, and a more gradual decrease for the other seven cements. In all cases the decrease, in turn, became slower as time progressed.

It is interesting to observe (column 7) that the eight cements, which differed considerably in oxide composition and markedly in calculated compound composition (table 1), reacted with water in the early periods to form calcium aluminate solutions with a molar ratio, $\mathrm{CaO} / \mathrm{Al}_{2} \mathrm{O}_{3}$, of approximately 1 . Except for experiments 6 to 8 , inclusive, for cement 7 , the average molar ratio of the other 65 solutions was 1.15 , with a range 1.06 to 1.29 , for periods up to and including $12 \mathrm{hr}$. The lime in solution in excess of $\mathrm{CaO} \cdot \mathrm{Al}_{2} \mathrm{O}_{3}$, as grams of $\mathrm{CaO}$ per liter, (column 9) averaged 0.1175 , and the $p \mathrm{H}$ of these solutions (column 11) averaged 11.25. At the later periods, the molar ratio, $\mathrm{CaO} / \mathrm{Al}_{2} \mathrm{O}_{3}$, in solution had increased, with a simultaneous increase in $p \mathrm{H}$ to 11.6 to 11.7 , even though the actual quantities of both alumina and lime in solution had decreased. It should be noted (columns 9 and 11) that the increase in $p \mathrm{H}$ is accompanied by a corresponding increase in lime in solution over that calculated to be in combination with the alumina as monocalcium aluminate. A more detailed discussion of this relation will be presented later.

Turning now to a consideration of the determined and calculated data of columns B of table 2 in comparison with those of columns A of the same table, it can be seen that changes identical with those described above also took place in the metastable solutions that had been filtered from the reaction mixtures and subsequently had approached a more steady state on standing. Part of the alumina and lime had precipitated from the clear metastable filtrates, leaving "equilibrium" solutions similar in composition to those obtained when the aluminous cements had been left in contact with water from 7 to 28 days. The molar ratio of lime to alumina increased as the metastable solutions approached equilibrium on standing, as can be noted from a comparison of the values of column 7 with those of column 8 . This was accompanied by an increase in $p \mathrm{H}$ to about 11.75 , a value slightly greater than that obtained for the solutions filtered from the reaction mixtures at the later periods up to 28 days.

From columns 4 and 6 , table 2 (again excluding experiments 6 to 8 for cement 7 ) the average con- centration of the calcium aluminate solutions at the "steady state" is $0.19 \mathrm{~g}$ of $\mathrm{Al}_{2} \mathrm{O}_{3}$ and $0.46 \mathrm{~g}$ of $\mathrm{CaO}$ per liter, which is very close to the composition of point B (fig. 1) obtained with the pure aluminates. The average molar ratio, $\mathrm{CaO} / \mathrm{Al}_{2} \mathrm{O}_{3}$, in the precipitate (column 13 in table 2 ) was 0.66 .

In figure 2 the quantities of alumina and lime dissolved in water (recorded in columns 3 and 5 of table 2) and the $p \mathrm{H}$ of the solutions (column 11) are plotted against the time of contact of the cement with water up to $24 \mathrm{hr}$. The similarity of the pattern of reaction of these cements, differing widely in composition, is worthy of note.

In figure 3 the concentration of alumina in solution at the different time periods (column 3, table 2) is plotted against the concentration of lime in solution (column 5, table 2). In this figure, as in figure 1 , the data adjacent to the plotted points indicate the time of shaking before filtering. The closed circles indicate that the concentration of the solution at the time of filtering was increasing, and the open circles that it was decreasing. The crosses

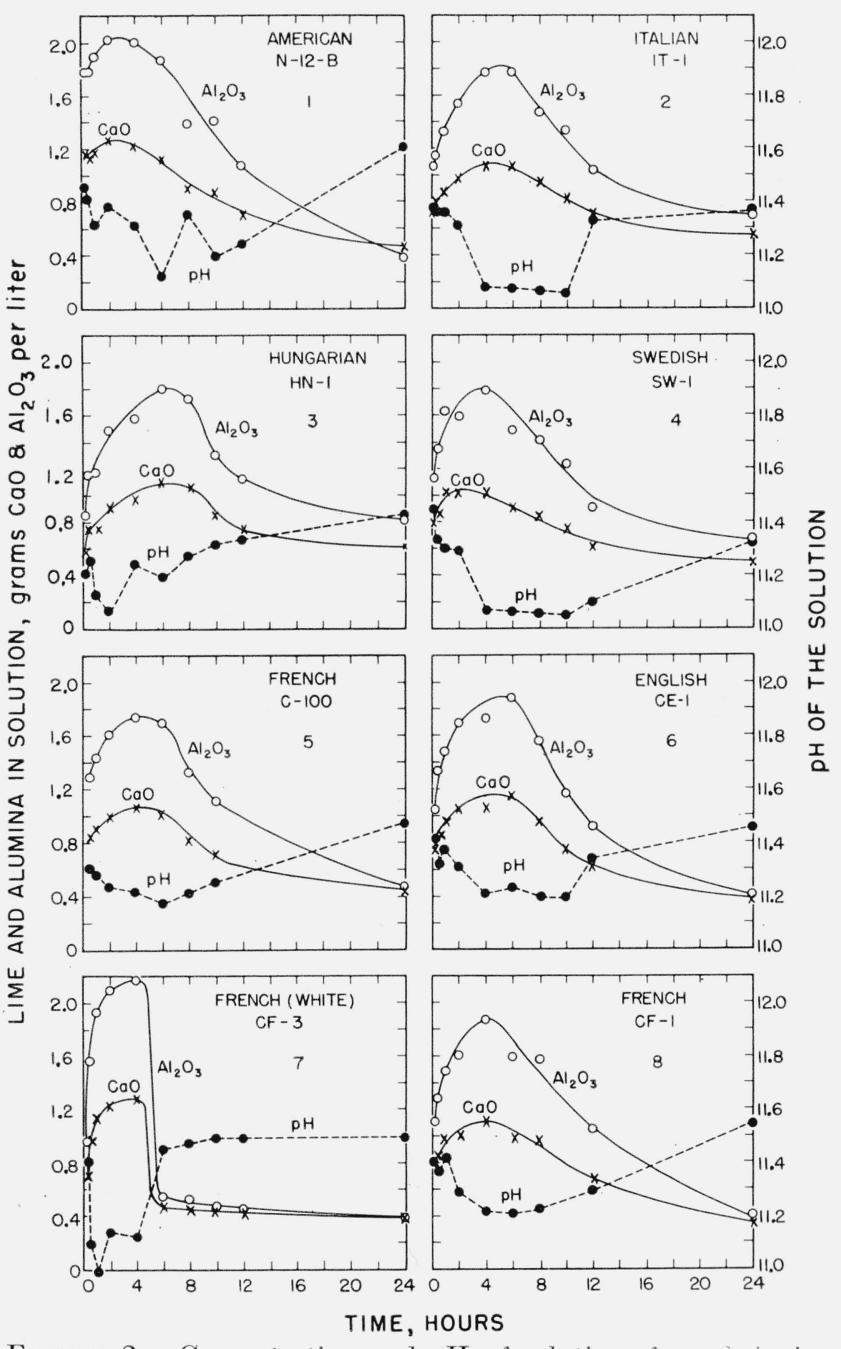

FIGURE 2. Concentration and $p \mathrm{H}$ of solutions formed during the first 24 hours from the reaction of water on aluminous cements. 
represent the compositions of solutions after attainment of a steady state (columns 4 and 6 of table 2 ). Note the marked similarity of paths of the reaction for the eight aluminous cements, and their close resemblance to the composite path of the three anhydrous calcium aluminates, shown in figure 1 .

The precipitates, for which the $\mathrm{C} / \mathrm{A}$ ratios are given in column 13 of table 2 , were examined microscopically. They were similar to the precipitates separated from the solutions obtained on shaking the pure aluminates with water, but with minor differences as noted below. The precipitates were composed almost wholly of two phases (A and B) with minor amounts of three others. A description follows:

(A) Flat, hexagonal plates, often spherulites; uniaxial, negative; $\omega=1.52$ to 1.53 . The individual crystals were extremely small, especially when precipitated from the more concentrated solutions. When oriented edgewise they appeared like short needles. This phase is believed to be $2 \mathrm{CaO} \cdot \mathrm{Al}_{2} \mathrm{O}_{3} \cdot 8 \mathrm{H}_{2} \mathrm{O}$.

(B) Amorphous material, apparently colloidal aggregates often in spheroidal form in irregular lumps. These round isotropic pellets were often very minute $(<0.005 \mathrm{~mm})$. As in the case of the hexagonal plates, the finer sized pellets precipitated from the more concentrated solutions. The spherules occurred as individuals or as linked groups. The index of refraction could not be determined because of the presence of a thin shell with higher index than the interior. The index of the shell was about $1.570 \pm 0.003$. This value was somewhat higher than that of the shell of the pellets formed from the aluminate solutions when anhydrous calcium aluminates were the starting materials. The higher index of refraction of the shell may be associated with the time of aging of the precipitated material. It may be recalled that the solutions had stood 4 to 5 months, as compared with 2 to 3 weeks for those obtained from the pure aluminates. The index of the shell is close to that of gibbsite $\left(\mathrm{Al}_{2} \mathrm{O}_{3} \cdot 3 \mathrm{H}_{2} \mathrm{O}\right.$; mean index 1.573); the latter, however, is birefringent.

The amorphous material also occurred in thin flakes, especially in material that had precipitated slowly (passing approximately from A to B in fig. 1). Like the pellets, the flakes had a thin shell of higher index of refraction, at times as high as 1.57 but generally lower. The film often covered the pellets and the hexagonal plates (phase $\mathrm{A}$ ), indicating that
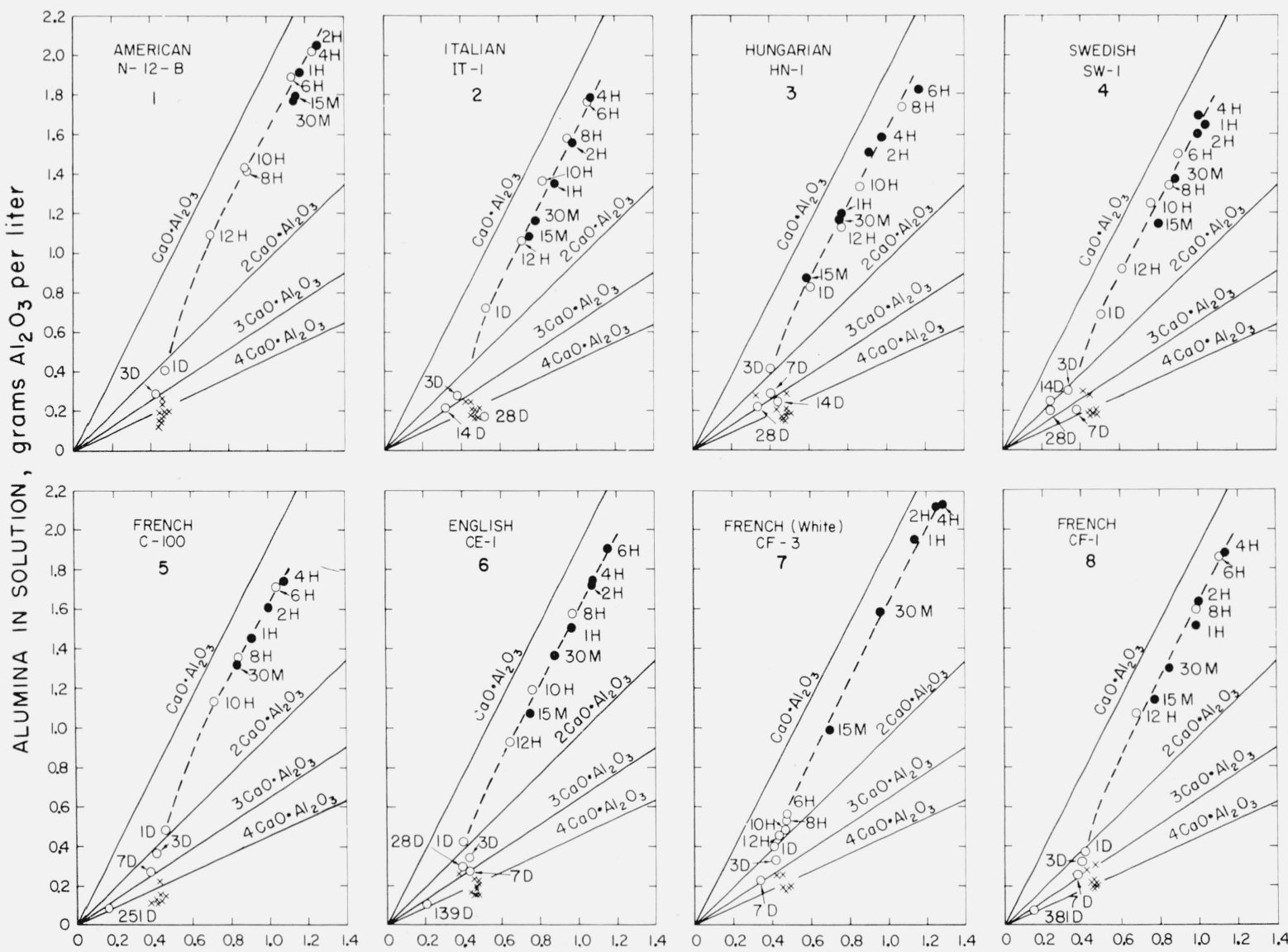

LIME IN SOLUTION, grams CaO per liter

Figure 3. Composition of solutions resulting from the reaction of water on aluminous cements.

Notations adjacent to plotted points indicate time in minutes, hours, or days. 
it had formed subsequently. Both the film and the pellets are believed to be a form of hydrated alumina.

(C) Calcite. This occurred in very small amounts and only in a few of the samples.

(D) İsometric crystals of $3 \mathrm{CaO} \cdot \mathrm{Al}_{2} \mathrm{O}_{3} \cdot 6 \mathrm{H}_{2} \mathrm{O}$, index very close to 1.605 . This phase was found in small amounts in about half the precipitates. It occurred more frequently than in the precipitates from the solutions obtained with the anhydrous aluminates. This may be associated with the longer period of aging. The isometric crystals were found in the precipitates formed from metastable solutions of various concentrations. Some of the better developed crystals, however, were formed from the more dilute solutions and often occurred on the flakes of hydrated alumina. This may indicate that they were formed subsequent to the flakes. Figure 4 shows some of these crystals on flakes of hydrated alumina. It also shows the characteristic pellets of hydrated alumina as well as some well-developed hexagonal plates.

(E) Calcium sulfo-aluminate, $3 \mathrm{CaO} \cdot \mathrm{Al}_{2} \mathrm{O}_{3} \cdot 3 \mathrm{CaSO}_{4}$ $32 \mathrm{H}_{2} \mathrm{O}$. This occurred as long birefringent needles $(\omega=1.465 ; \epsilon=1.458)$ in only three samples from solutions obtained with the Hungarian cement HN-1. It was an abundant phase in the precipitate from the solution obtained by shaking this cement with water for $15 \mathrm{~min}$. It was not nearly as abundant in the 30 -min preparation, still less abundant in the 1 -hr preparation, and absent in the 2 -hr preparation and all preparations thereafter. It should be recalled that this cement was burned under oxidizing condition. The total sulfur as $\mathrm{SO}_{3}$ was 0.94 per-

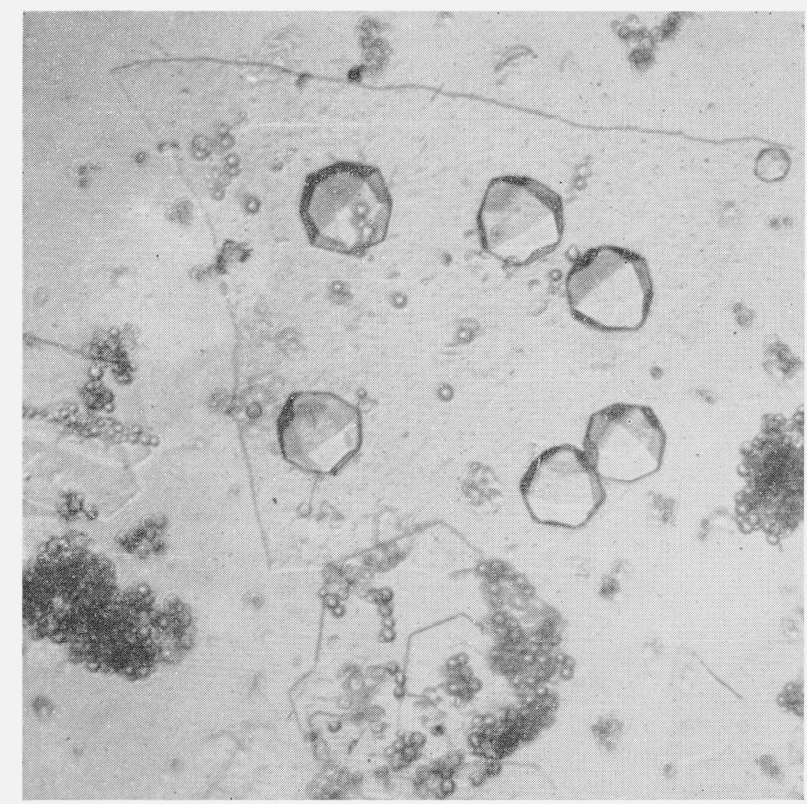

FIgURE 4. Photomicrograph showing isometric $3 \mathrm{CaO} \cdot \mathrm{Al}_{2} \mathrm{O}_{3}$. $6 \mathrm{H}_{2} \mathrm{O}$ embedded in flakes of hydrated alumina, also pellets of hydrated alumina and a few crystals of $2 \mathrm{CaO} \cdot \mathrm{Al}_{2} \mathrm{O}_{3} \cdot 8 \mathrm{H}_{2} \mathrm{O}$ (hexagonal plates). cent (table 1), and there was no evidence of the presence of any sulfide sulfur.

To summarize, it appears that the reactions between water and the aluminous cements, as in the case of the anhydrous calcium aluminates, are in part related to the precipitation of hydrated alumina and a crystalline hydrated calcium aluminate (probably $2 \mathrm{CaO} \cdot \mathrm{Al}_{2} \mathrm{O}_{3} \cdot 8 \mathrm{H}_{2} \mathrm{O}$ ) from metastable and supersaturated monocalcium aluminate solutions.

\subsection{Nature of the Calcium Aluminate Solutions}

In an earlier paper [4] it was shown that the alumina exists in solution as the calcium salt of monobasic aluminic acid, and that the quantity of $\mathrm{CaO}$ in excess of this salt (that is, as calcium hydroxide) determines the $p \mathrm{H}$. The data in columns 9 to 12 of table 2 support this conclusion. Referring to figure 1 , the $p \mathrm{H}$ values of solutions along the line $\mathrm{A}^{\prime} \mathrm{A}$ range from about 11.1 to 11.4 . Although the total $\mathrm{CaO}$ in solution decreases slightly from $\mathrm{A}$ to $\mathrm{B}$, the $p \mathrm{H}$ rises to 11.7 to 11.8 at $\mathrm{B}$, owing to the increase in $\mathrm{CaO}$ in excess of monocalcium aluminate.

A detailed discussion of the hydrolysis and ionization of the calcium aluminate in solution was given in the earlier paper [4]. As reported therein, the degree of hydrolysis, $h$, of the aluminate in solution was calculated from the equation

$$
\frac{h^{2} C_{s}}{1-h}=\frac{K_{W}}{K_{A}}=K_{H},
$$

in which $C_{s}$ is the concentration, in moles per liter of the dissolved $\mathrm{Ca}\left(\mathrm{AlO}_{2}\right)_{2}$ (or $\left.\mathrm{CaO} \cdot \mathrm{Al}_{2} \mathrm{O}_{3}\right), K_{W}$ is the ionization constant of water, $K_{A}$ is the ionization constant of $\mathrm{HAlO}_{2}$, and $K_{H}$ is the hydrolysis constant of $\mathrm{Ca}\left(\mathrm{AlO}_{2}\right)_{2}$. This equation is approximate because of the assumption that the degree of ionization of the base, $\mathrm{Ca}(\mathrm{OH})_{2}$, is the same as that of the unhydrolyzed $\mathrm{Ca}\left(\mathrm{AlO}_{2}\right)_{2}$. The value $K_{A}=1 \times$ $10^{-9}$ was adopted as the approximate average of values reported in the literature. The value of $h$ has now been recalculated on the basis that $K_{\mathrm{A}}=$ $1 \times 10^{-10}$, as reported by Slade [19]. Taking as a specific example cement 1 at $2 \mathrm{hr}$, the point of maximum concentration (see table 2), and basing the calculations on the concentration of $\mathrm{Al}_{2} \mathrm{O}_{3}$ as equivalent to the monocalcium aluminate in solution,

$$
\frac{h^{2}(0.02014)}{1-h}=\frac{10^{-14}}{10^{-10}}=10^{-4} \text {. }
$$

From this equation, $h$ is calculated to be 0.068 ; that is, the percentage of hydrolysis is 6.8. This means that $0.02014 \times 0.068=0.001370$ mole, or 0.002740 equivalent, of $\mathrm{Ca}(\mathrm{OH})_{2}$ results from the initial hydrolysis of monocalcium aluminate. To express this quantity of $\mathrm{Ca}(\mathrm{OH})_{2}$ in terms of $p \mathrm{H}$ it is necessary to know its degree of ionization into $\mathrm{Ca}^{++}$and $\mathrm{OH}^{-}$in the presence of the unhydrolyzed monocalcium aluminate. While the degree of ionization is not known, some other calculations, based on $p \mathrm{H}$ measurements, have indicated that the calcium hydroxide behaves as though it were about 60 percent ionized in the presence of the above 
quantity of monocalcium aluminate. Accordingly, with an assumed ionization of 60 percent, the $p \mathrm{H}$ of the hydrolyzed calcium aluminate solution has been calculated as follows:

$$
\begin{aligned}
p H & =\log _{\left[\mathrm{H}^{+}\right]} \frac{1}{=}=\log \frac{\left[\mathrm{OH}^{-}\right]}{1 \times 10^{-14}} \\
& =\log (0.002740 \times 0.6)+\log 10^{14} \\
& =\log (0.001644)+14 \\
& =(7.216-10)+14=11.22 .
\end{aligned}
$$

Similar calculations for the other seven cements at the point of maximum solubility give $p H$ values ranging from 11.20 to 11.25 . The spread in corresponding observed values for the eight cements is 11.08 to 11.39 , with an average of 11.20 . In general, the agreement is fair for all the solutions obtained on reaction periods up to 10 or $12 \mathrm{hr}$.

The $p \mathrm{H}$ values obtained in corresponding experiments with the anhydrous calcium aluminates averaged 11.24 , again illustrating the close relation between these and the aluminous cements in respect to their reactions with water.

It should be pointed out that one of the products of the hydrolysis of a monocalcium aluminate solution is hydrated alumina which is only sparingly soluble under the conditions of the experiments. This leaves a slight excess of calcium hydroxide which tends to prevent further hydrolysis. The net result is that the molar proportion of lime to alumina remaining in solution is always slightly in excess of 1 to 1 .

From the foregoing it is apparent that the aluminous cements, like the anhydrous calcium aluminates, react with water to form solutions of monocalcium aluminate. These undergo partial hydrolysis, forming hydrated alumina and leaving a slight excess of $\mathrm{Ca}(\mathrm{OH})_{2}$ in solution. The solutions also are metastable with respect to crystalline calcium aluminate hydrates. The one that precipitates first, under the conditions of these experiments, is the $\mathrm{C}_{2} \mathrm{~A}$-hydrate. The process decreases the amount of excess $\mathrm{Ca}(\mathrm{OH})_{2}$ in solution, thus favoring further precipitation of hydrated alumina, until a steady state eventually is attained. The molar ratio, $\mathrm{CaO} / \mathrm{Al}_{2} \mathrm{O}_{3}$, in the precipitates obtained in this study (table 2 , column 13) was 0.66 . This is approximately equivalent to 1 mole of $\mathrm{C}_{2} \mathrm{~A}$-hydrate to 2 moles of hydrated $\mathrm{Al}_{2} \mathrm{O}_{3}$.

\section{Equilibria in the System $\mathrm{CaO}-\mathrm{Al}_{2} \mathrm{O}_{3}-\mathrm{H}_{2} \mathrm{O}$}

The hydrated calcium aluminates have been the subject of many investigations and the data have been assembled on numerous occasions. Wells, Clarke, and McMurdie [6] in their study of the system $\mathrm{CaO}-\mathrm{Al}_{2} \mathrm{O}_{3}-\mathrm{H}_{2} \mathrm{O}$ assembled much of the data on these compounds. More recently the present knowledge of this subject has been ably summarized by Steinour [8]. Consequently, it will be necessary to take up at this time only the factors that have a bearing on the problem at hand. It should be stated, however, that the situation in regard to the com- pounds containing alumina is complicated by marked similarities in the crystalline structures and optical properties of various calcium aluminate hydrates. Also, the calcium aluminate hydrates and other more complex aluminates tend to form in states which though mestastable are nevertheless highly persistent.

\subsection{Calcium Aluminate Hydrates}

Among the numerous compositions that have been reported for the various calcium aluminate hydrates, the following appear best established:

$$
\begin{aligned}
& 6 \mathrm{CaO} \cdot \mathrm{Al}_{2} \mathrm{O}_{3} \cdot 33 \mathrm{H}_{2} \mathrm{O} \\
& 5 \mathrm{CaO} \cdot \mathrm{Al}_{2} \mathrm{O}_{3} \cdot 34 \mathrm{H}_{2} \mathrm{O} \\
& 4 \mathrm{CaO} \cdot \mathrm{Al}_{2} \mathrm{O}_{3} \cdot 12-14 \mathrm{H}_{2} \mathrm{O} \\
& 3 \mathrm{CaO} \cdot \mathrm{Al}_{2} \mathrm{O}_{3} \cdot 18-21 \mathrm{H}_{2} \mathrm{O} \\
& 3 \mathrm{CaO} \cdot \mathrm{Al}_{2} \mathrm{O}_{3} \cdot 10-12 \mathrm{H}_{2} \mathrm{O} \\
& 3 \mathrm{CaO} \cdot \mathrm{Al}_{2} \mathrm{O}_{3} \cdot 6 \mathrm{H}_{2} \mathrm{O} \\
& 2 \mathrm{CaO} \cdot \mathrm{Al}_{2} \mathrm{O}_{3} \cdot 7-9 \mathrm{H}_{2} \mathrm{O} \\
& \mathrm{CaO} \cdot \mathrm{Al}_{2} \mathrm{O}_{3} \cdot 10 \mathrm{H}_{2} \mathrm{O} .
\end{aligned}
$$

The variable water-content probably reflects differences in the mode of drying of the preparations. Lower hydrates have been reported, resulting from more vigorous drying.

The first, second, and fourth members of this list, so far as known, have not been prepared in the absence of substances extraneous to the system $\mathrm{CaO}-\mathrm{Al}_{2} \mathrm{O}_{3}-\mathrm{H}_{2} \mathrm{O}$. In any case they probably are not pertinent to the present subject, and will not be further discussed here.

With the exception of $3 \mathrm{CaO} \cdot \mathrm{Al}_{2} \mathrm{O}_{3} \cdot 6 \mathrm{H}_{2} \mathrm{O}$, which belongs to the cubic system, all the various calcium aluminate hydrates crystallize with hexagonal or lower symmetry. Whether a particular crystalline species actually is hexagonal or of lower symmetry seems less important than the fact that all these compounds are apparently structurally related. Consequently, it will be convenient to refer to the hexagonal-appearing crystals simply as "hexagonal."

It has frequently been pointed out that the hexagonal aluminates are difficult to diffentiate under the microscope, because the refractive indices vary more with the degree of drying than between the various species. Also there may be intergrowths of two species. X-ray diffraction patterns have been more helpful, but even here some confusion exists, because the patterns are closely related. Nevertheless, it is possible to identify both the $\mathrm{C}_{2} \mathrm{~A}$-hydrate and the CA-hydrate by their low-angle reflections.

The compound $\mathrm{CaO} \cdot \mathrm{Al}_{2} \mathrm{O}_{3} \cdot 10 \mathrm{H}_{2} \mathrm{O}$ was reported by Assarsson [20] over 20 years ago, but its importance appears to have been overlooked by other investigators until recently. A possible reason for this oversight is the fact that the most distinctive line on the X-ray pattern of the CA-hydrate occurs at about $3^{\circ} \theta$, which is below the working range of earlier X-ray diffraction equipment. Longuet [21] in a discussion of a paper at the London Symposium on the Chemistry of Cement, reported the preparation of a CA-hydrate for which he indicated the most probable formula to be $\mathrm{CaO} \cdot \mathrm{Al}_{2} \mathrm{O}_{3} \cdot 7 \mathrm{H}_{2} \mathrm{O}$. The X-ray 
pattern reported was identical with one earlier given by Brocard [22], who then regarded it, however, as possibly representing a new $\mathrm{C}_{2} \mathrm{~A}$-hydrate. Patterns in good agreement with those reported by Longuet and Brocard have been recently obtained at the Bureau on hydrated pastes of monocalcium aluminate and on aluminous cements. The pattern given by Assarsson [16] for his $\mathrm{CAH}_{10}$ is similar to one obtained at the Bureau on a preparation believed to be a mixture of $\mathrm{C}_{2} \mathrm{~A}$ - and $\mathrm{CA}$-hydrates, the main difference being the absence of the $3^{\circ} \theta$ line from Assarsson's pattern. This suggests the possibility that the CA-hydrates of Assarsson, Brocard, and Longuet are the same species, and that the preparation used by Assarsson for his X-ray pattern may have contained some $\mathrm{C}_{2} \mathrm{~A}$-hydrate.

The other three hexagonal compounds, the $\mathrm{C}_{4} \mathrm{~A}-$, $\mathrm{C}_{3} \mathrm{~A}$-, and $\mathrm{C}_{2} \mathrm{~A}$-hydrates, have been discussed by numerous investigators. Present-day knowledge and theories concerning these hydrates have been reviewed by Steinour [8].

\subsection{Hydrated Alumina $\left(\mathrm{Al}_{2} \mathrm{O}_{3} \cdot \mathrm{aq}\right)$}

It has been previously shown [6,7] that gibbsite, $\mathrm{Al}_{2} \mathrm{O}_{3} \cdot 3 \mathrm{H}_{2} \mathrm{O}$ is the stable form of hydrated alumina in the system $\mathrm{CaO}-\mathrm{Al}_{2} \mathrm{O}_{3}-\mathrm{H}_{2} \mathrm{O}$ over a considerable range in temperature, and its equilibrium curves at various temperatures have been established. On the other hand, amorphous hydrated alumina is an ill- defined material, the properties of which vary widely with mode of preparation and subsequent treatment. The work described below refers to an intermediate stage, not as well defined as macrocrystalline gibbsite, yet sufficiently stable to permit tracing a metastable solubility curve in the equilibrium diagram. X-ray diffraction patterns indicate the gradual transformation of amorphous hydrated alumina to gibbsite. The intermediate form therefore will be referred to as microcrystalline gibbsite, or $\mathrm{Al}_{2} \mathrm{O}_{3}$.aq. It appears to have an important bearing on the behavior of the cementitious aluminates.

In this study the approach to metastable equilibrium was from supersaturation. Calcium aluminate solutions were prepared at $21^{\circ} \mathrm{C}$ as described above, filtered, analyzed, and diluted with measured amounts of distilled water to furnish a series of solutions of decreasing concentration. From the more concentrated solutions a separation of solid phases occurred fairly rapidly at first, and then more slowly, as the solutions gradually approached a steady state. As the initial concentration of the diluted solutions decreased, the rate of precipitation decreased. Dilute monocalcium aluminate solutions having less than $0.15 \mathrm{~g}$ of $\mathrm{CaO}$ per liter remained clear for months and showed but little tendency to liberate hydrated alumina as a solid phase.

Table 3 gives the solubility relations pertaining to the $\mathrm{Al}_{2} \mathrm{O}_{3}$.aq precipitated, together with the

TABLE 3. Solubility relations pertaining to microcrystalline hydrated alumina, $\mathrm{Al}_{2} \mathrm{O}_{3} \cdot \mathrm{aq}$, as ascertained from a state of supersaturation at a constant temperature of $21^{\circ} \mathrm{C}$, together with the refractive indices of the products thus formed

\begin{tabular}{|c|c|c|c|c|c|c|c|c|c|c|c|c|c|}
\hline \multirow{2}{*}{$\begin{array}{c}\text { Experi- } \\
\text { ment }\end{array}$} & \multicolumn{3}{|c|}{$\begin{array}{l}\text { Composition of initial } \\
\text { solutions }\end{array}$} & \multirow{2}{*}{$\begin{array}{l}\text { Time } \\
\text { to ap- } \\
\text { proach } \\
\text { meta- } \\
\text { stable } \\
\text { equilik- } \\
\text { rium }\end{array}$} & \multicolumn{3}{|c|}{$\begin{array}{l}\text { Composition of resulting } \\
\text { solutions }\end{array}$} & \multicolumn{3}{|c|}{$\begin{array}{l}\text { Composition of precipitated } \\
\text { material }\end{array}$} & \multicolumn{2}{|c|}{$\begin{array}{l}\text { Indices of } \\
\text { refraction }\end{array}$} & \multirow{2}{*}{ Remarks } \\
\hline & $\mathrm{Al}_{2} \mathrm{O}_{3}$ & $\mathrm{CaO}$ & $\begin{array}{c}\text { Molar } \\
\text { ratio, } \\
\mathrm{CaO} / \mathrm{Al}_{2} \mathrm{O}_{3}\end{array}$ & & $\mathrm{Al}_{2} \mathrm{O}_{3}$ & $\mathrm{CaO}$ & $\begin{array}{c}\text { Molar } \\
\text { ratio, } \\
\mathrm{CaO} / \mathrm{Al}_{2} \mathrm{O}_{3}\end{array}$ & $\begin{array}{c}\text { Molar } \\
\text { ratio } \\
\mathrm{CaO} / \mathrm{Al}_{2} \mathrm{O}_{3} \\
\text { (calculated) }\end{array}$ & $\begin{array}{l}\text { Molar } \\
\text { ratio, } \\
{\mathrm{CaO} / \mathrm{Al}_{2} \mathrm{O}_{3}}_{\text {(analysis) }}\end{array}$ & $\begin{array}{l}\text { Molar } \\
\text { ratio, } \\
\mathrm{H}_{2} \mathrm{O} / . \mathrm{l}_{2} \mathrm{O}_{3} \\
\text { (analysis) }\end{array}$ & $\mathrm{Al}_{2} \mathrm{O}_{3} \cdot \mathrm{aq}$ & $\begin{array}{c}\text { Hex- } \\
\text { agonal }\end{array}$ & \\
\hline 1 & 2 & 3 & 4 & 5 & 6 & 7 & 8 & 9 & 10 & 11 & 12 & 13 & 14 \\
\hline $1 \ldots$ & $\begin{array}{l}\text { g/liter } \\
0.3751\end{array}$ & $\begin{array}{l}\text { g/liter } \\
0.2180\end{array}$ & 1. 06 & $\begin{array}{c}\text { Days } \\
291\end{array}$ & $\begin{array}{l}g / \text { liter } \\
0.1475\end{array}$ & $\begin{array}{l}g / \text { liter } \\
0.2090\end{array}$ & 2. 58 & 0.07 & 0.15 & 3. 89 & 1. 545 & $1.53-$ & $\begin{array}{l}\mathrm{Al}_{2} \mathrm{O}_{3} \cdot \text { aq as pellets, trace } \\
\text { isometric } 3 \mathrm{CaO} \cdot \mathrm{Al}_{2} \mathrm{O}_{3} \text {. } \\
6 \mathrm{H}_{2} \mathrm{O} \text {. }\end{array}$ \\
\hline $2 \ldots$ & .4220 & .2490 & 1.07 & 300 & .1570 & .2310 & 2. 67 & .12 & .17 & 3. 30 & 1. 507 & & $\begin{array}{l}\mathrm{Al}_{2} \mathrm{O}_{3} \cdot \mathrm{aq} \text { as pellets, trace } \\
\mathrm{CaCO}_{3} \text {. }\end{array}$ \\
\hline $3 \ldots$ & .4741 & .2765 & 1.06 & 300 & .0925 & 2375 & 4. 67 & .19 & .18 & 3.43 & 1. 533 & 1.53 & $\begin{array}{l}\mathrm{Al}_{2} \mathrm{O}_{3} \cdot \mathrm{aq} \text { as pellets, tr. } \\
\text { hexagonal. }\end{array}$ \\
\hline $4 \ldots$ & .5026 & .2986 & 1.08 & 161 & .1250 & .2700 & 3. 93 & .14 & .... & ...- & 1. 550 & $1.53-$ & $\begin{array}{l}\mathrm{Al}_{2} \mathrm{O}_{3} \cdot \mathrm{aq} \text { as pellets most- } \\
\text { ly; also as flakes. }\end{array}$ \\
\hline $5 \ldots$ & .6278 & .3718 & 1. 08 & 309 & .1130 & .3015 & 4. 54 & .25 & .26 & 3.53 & 1. 548 & $1.53+$ & $\begin{array}{l}\mathrm{Al}_{2} \mathrm{O}_{3} \cdot \mathrm{aq} \text { as pellets, few } \\
\text { hexagonal plates. }\end{array}$ \\
\hline 6 & .5755 & .3408 & 1.08 & 309 & .1350 & .3125 & 4. 22 & .12 & .17 & 3.49 & 1. 545 & 1. $53-$ & $\begin{array}{l}\mathrm{Al}_{2} \mathrm{O}_{3} \cdot \mathrm{aq} \text { as pellets, with } \\
\text { few flakes, tr. calcite. }\end{array}$ \\
\hline 7. & .6332 & .4070 & 1.17 & $\left\{\begin{array}{r}344 \\
514 \\
1,081\end{array}\right.$ & $\begin{array}{l}.1420 \\
\\
1310 \\
.0915\end{array}$ & $\begin{array}{l}.3230 \\
\\
.3070 \\
.2480\end{array}$ & $\begin{array}{l}\text { 4. } 13 \\
\text { 4. } 26 \\
\text { 4. } 92\end{array}$ & $\begin{array}{r}.31 \\
.36 \\
.53\end{array}$ & $+\cdots$ & - n & $\begin{array}{l}\text { 1. } 475 \\
\text { 1. } 50- \\
\text { 1. } 485\end{array}$ & - & $\begin{array}{l}\mathrm{Al}_{2} \mathrm{O}_{3} \cdot \text { aq as well-formed } \\
\text { pellets. } \\
\text { Do. } \\
\text { Do. }\end{array}$ \\
\hline $8 \ldots$ & .6402 & .3921 & 1.11 & $\left\{\begin{array}{r}394 \\
514 \\
1,081\end{array}\right.$ & $\begin{array}{r}.1440 \\
.1300 \\
.0545\end{array}$ & $\begin{array}{r}.3330 \\
.3140 \\
.1820\end{array}$ & $\begin{array}{l}\text { 4. } 20 \\
\text { 4. } 39 \\
6.07\end{array}$ & $\begin{array}{l}.22 \\
.28 \\
.65\end{array}$ & $-\cdots$ & $-\cdots$ & $\begin{array}{l}1.470 \\
1.470 \\
1.555\end{array}$ & - & $\begin{array}{l}\mathrm{Al}_{2} \mathrm{O}_{3} \cdot \mathrm{aq} \text { as pellets most- } \\
\text { ly with few flakes. } \\
\mathrm{Al}_{2} \mathrm{O}_{3} \cdot \mathrm{aq} \text { as pellets with } \\
\text { flakes increasing. } \\
\text { Do. }\end{array}$ \\
\hline $9 \ldots$ & .6521 & .3965 & 1.11 & $\left\{\begin{array}{r}205 \\
394 \\
514 \\
1,081\end{array}\right.$ & $\begin{array}{l}.1400 \\
.1130 \\
.1010 \\
.0300\end{array}$ & $\begin{array}{l}.3410 \\
.3100 \\
.2900 \\
.2265\end{array}$ & $\begin{array}{l}\text { 4. } 43 \\
\text { 4. } 99 \\
\text { 5. } 22 \\
6.86\end{array}$ & $\begin{array}{l}.20 \\
.29 \\
.35 \\
.52\end{array}$ & $\begin{array}{l}\cdots \\
\cdots-- \\
\cdots-\end{array}$ & $\begin{array}{ll}\cdots \\
\cdots-- \\
\cdots-\end{array}$ & $\begin{array}{l}\text { 1. } 550 \\
1,550 \\
\text { 1. } 555 \\
\text { 1. } 560\end{array}$ & 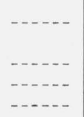 & $\begin{array}{c}\mathrm{A}_{2} \mathrm{O}_{3} \cdot \mathrm{aq} \text { as pallets, no } \\
\text { hexagonal, no isometric. } \\
\text { Do. } \\
\text { Do. } \\
\text { Do. }\end{array}$ \\
\hline $10 \ldots$ & .7902 & .4608 & 1.06 & 300 & .1450 & .4000 & 5. 02 & .17 & .19 & 3.57 & 1. 563 & 1. 535 & $\begin{array}{l}\mathrm{Al}_{2} \mathrm{O}_{3} \cdot \text { aq as pellets, hex- } \\
\text { agonal plates small. }\end{array}$ \\
\hline $11 \ldots$ & .7200 & .4880 & 1. 23 & 443 & $.14 i 0$ & .4070 & 5. 40 & 22 & ...- & $\ldots$ & - n. & - n & $\begin{array}{l}\text { Not examined micro- } \\
\text { scopically. }\end{array}$ \\
\hline $12 \ldots$ & .8270 & .5380 & 1. 18 & 96 & .1805 & .7000 & 4.62 & .22 & -... & $\cdots$ & & -.. & Do. \\
\hline
\end{tabular}


indices of refraction of the products thus formed. Column 9 gives the molar ratio, $\mathrm{CaO} / \mathrm{Al}_{2} \mathrm{O}_{3}$, calculated from the data of columns 2 and 3 in conjunction with those of columns 6 and 7 . Column 10 gives this same ratio obtained by direct analysis of the precipitated material, and column 11 gives the molar ratio, $\mathrm{H}_{2} \mathrm{O} / \mathrm{Al}_{2} \mathrm{O}_{3}$, obtained by direct analysis. The data are arranged in order of increasing quantity of lime in solution after precipitation (column 7). When there were several time periods (preparations 7,8 , and 9 ), the arrangement pertains to the earliest recorded time period.

In figure 5, the compositions of the original solutions are indicated by closed circles, and crosses show the compositions of the solutions after precipitation of a portion of the alumina as a solid phase. The figures accompanying the lines connecting the original and subsequent compositions give the calculated molar ratios, $\mathrm{CaO} / \mathrm{Al}_{2} \mathrm{O}_{3}$, in the materials precipitated. The connecting lines do not necessarily reveal the actual course of precipitation.

For the most part the precipitated material consisted of small pellets or spherulites of hydrated alumina with occasional flakes of the same material. The indices of refraction of the hydrated alumina when first formed, although variable, averaged about 1.50 , and later increased as the hydrated alumina aged. As in the work described earlier, the refractive index of the surface of both pellets and flakes increased more rapidly than that of the interior. Consequently, it was rather difficult to determine the indices accurately. However, the refractive index of the outside shell increased to as much as 1.56 , and that of the interior was definitely less.

The gradual increase in refractive index is in line with results given in previous papers $[4,6]$. Assarsson [23] reported similar findings, and, on the basis of $\mathrm{X}$-ray analysis, came to the conclusion that gibbsite was the final product of the aging, even though his samples of hydrated alumina contained between 3 and 4 moles of $\mathrm{H}_{2} \mathrm{O}$ rather than the 3 prescribed

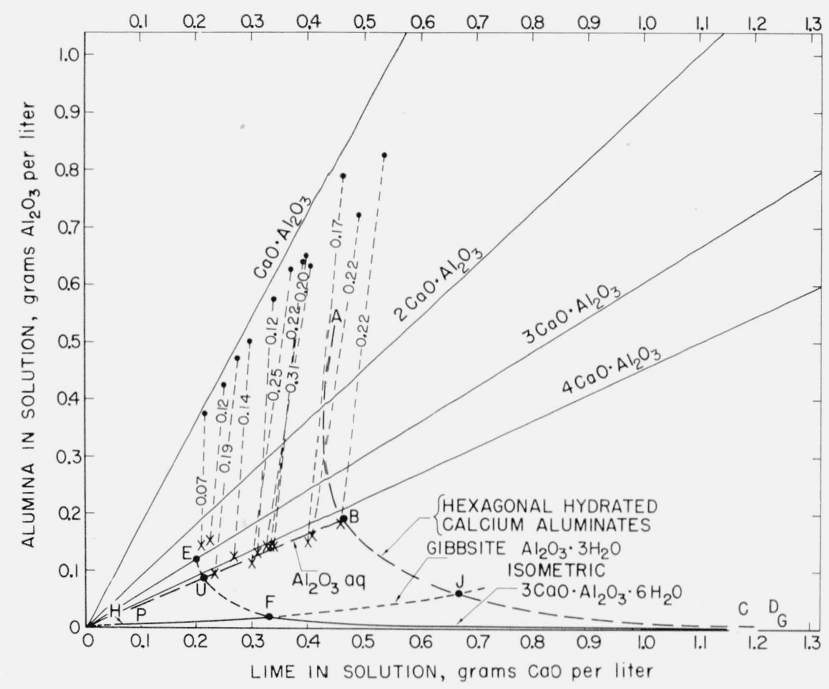

Figure 5. Solubility of $\mathrm{Al}_{2} \mathrm{O}_{2} \cdot \mathrm{aq}$ (represented by line PUB) in the system $\mathrm{CaO}-\mathrm{Al}_{2} \mathrm{O}_{3}-\mathrm{H}_{2} \mathrm{O}$ at $21^{\circ} \mathrm{C}$. for gibbsite, $\mathrm{Al}_{2} \mathrm{O}_{3} \cdot 3 \mathrm{H}_{2} \mathrm{O}$. The extra water he ascribed to adsorption.

X-ray diffraction patterns of samples of aged hydrated alumina were found in a former investigation [6], as well as in the present study, to contain the lines characteristic of gibbsite. The intensity of the lines increased as the hydrated alumina aged. It was noted also that the molar ratios, $\mathrm{H}_{2} \mathrm{O} / \mathrm{Al}_{2} \mathrm{O}_{3}$, were in many instances between 3 and 4 (see table 3 , column 11).

These studies show that the hydrated alumina that is formed is converted to gibbsite on aging. The conversion is, however, very slow at room temperatures. The product designated $\mathrm{Al}_{2} \mathrm{O}_{3} \cdot \mathrm{aq}$ thus appears to be essentially gibbsite but with a microcrystalline structure. As such its solubility would be expected to be greater than that of macrocrystalline gibbsite.

A few hexagonal crystals were also observed in some of the precipitates, also a little $\mathrm{C}_{3} \mathrm{AH}_{6}$ in one precipitate and traces of calcite in two others. The presence of these lime-bearing materials contributed to raising the molar ratio, $\mathrm{CaO} / \mathrm{Al}_{2} \mathrm{O}_{3}$, in the precipitates. In several instances (notably, from preparations 7,8 , and 9) the hexagonal plates that appeared at first, later disappeared or decreased in amount as separation of hydrated alumina progressed.

In figure 5 a line is drawn from $\mathrm{U}$ to $\mathrm{B}$ through the points indicated by crosses and extended from $\mathrm{U}$ to an undetermined point $\mathrm{P}$. The values from preparations 1 and 2 show concentrations of alumina in solution somewhat above PUB, but, as mentioned previously, the precipitation of hydrated alumina from the more dilute calcium aluminate solutions was very slow. Below a concentration of $0.15 \mathrm{~g}$ of $\mathrm{CaO}$ per liter the approach was so slow that the section of the curve UP could not be determined satisfactorily. For preparations 7, 8, and 9 the crosses represent the compositions of the solutions at 344 , 394 , and 205 days, respectively. At the later time periods (not shown in fig. 5), the precipitation curves changed direction and approached $\mathrm{U}$ in the general direction from $\mathrm{B}$ to $\mathrm{U}$. The location of the invariant point B from many determinations has already been discussed.

\subsection{The System $\mathrm{CaO}-\mathrm{Al}_{2} \mathrm{O}_{3}-\mathrm{H}_{2} \mathrm{O}$ at $21^{\circ} \mathrm{C}$}

Comprehensive equilibrium studies in the system $\mathrm{CaO}-\mathrm{Al}_{2} \mathrm{O}_{3}-\mathrm{H}_{2} \mathrm{O}$ have been attempted only relatively recently. The work in this field has been reviewed by Bessey [24] and by Steinour [8]. The former also reported the results of extensive investigations by Lea and Bessey in which attempts were made to reach equilibrium by various methods of approach. Although the results did not permit a thorough analysis of the metastable relationships, they gave a general picture in substantial agreement with a more detailed report made subsequently by Wells, Clarke, and McMurdie [6].

Recently, D'Ans and Eick [25] have published the results of their studies of the phase equilibrium relations in the system $\mathrm{CaO}-\mathrm{Al}_{2} \mathrm{O}_{3}-\mathrm{H}_{2} \mathrm{O}$. They made sufficient measurements to verify in the main those 
set forth by Wells, Clarke, and McMurdie. In their diagram they added three other solubility curves for three preparations of hydrated alumina. From their data, however, it is doubtful if they attained even what might be termed "metastable equilibrium."

Figure 6 is a diagram of the system $\mathrm{CaO}-\mathrm{Al}_{2} \mathrm{O}_{3}-\mathrm{H}_{2} \mathrm{O}$ at $21^{\circ} \mathrm{C}$ (Wells, Clarke, and McMurdie) [6], supplemented by the solubility curve for $\mathrm{Al}_{2} \mathrm{O}_{3}$.aq taken from figure 5. The solubility curves in regions of stable equilibria are represented by heavy solid lines. Upward extensions beyond the junction of these are shown by dashed lines because they represent metastable conditions. The only solid phases that have regions of true solubility are macrocrystalline gibbsite $\left(\mathrm{Al}_{2} \mathrm{O}_{3} \cdot 3 \mathrm{H}_{2} \mathrm{O}\right)$ from $\mathrm{H}$ to $\mathrm{F}$, isometric $3 \mathrm{CaO} \cdot \mathrm{Al}_{2} \mathrm{O}_{3} \cdot 6 \mathrm{H}_{2} \mathrm{O}$ from $\mathrm{F}$ to $\mathrm{V}$, and $\mathrm{Ca}(\mathrm{OH})_{2}$ from $\mathrm{V}$ to $\mathrm{C}$. Thus, $\mathrm{F}$ is a stable invariant point $(0.33 \mathrm{~g}$ of $\mathrm{CaO}$ and $0.02 \mathrm{~g}$ of $\mathrm{Al}_{2} \mathrm{O}_{3}$ per liter) between $\mathrm{Al}_{2} \mathrm{O}_{3} \cdot 3 \mathrm{H}_{2} \mathrm{O}$ and $3 \mathrm{CaO} \cdot \mathrm{Al}_{2} \mathrm{O}_{3}$. $6 \mathrm{H}_{2} \mathrm{O}$, and $\mathrm{V}$ between $3 \mathrm{CaO} \cdot \mathrm{Al}_{2} \mathrm{O}_{3} \cdot 6 \mathrm{H}_{2} \mathrm{O}$ and $\mathrm{Ca}(\mathrm{OH})_{2}$. The solubility of macrocrystalline $\mathrm{Ca}(\mathrm{OH})_{2}$ in pure water is represented by $\mathrm{C}$ as $1.15 \mathrm{~g}$ of $\mathrm{CaO}$ per liter. Consequently, from E to $\mathrm{F}, 3 \mathrm{CaO} \cdot \mathrm{Al}_{2} \mathrm{O}_{3} \cdot 6 \mathrm{H}_{2} \mathrm{O}$ is metastable in respect to gibbsite, and conversely from $\mathrm{F}$ to $\mathrm{J}$, gibbsite is metastable in respect to $3 \mathrm{CaO} \cdot \mathrm{Al}_{2} \mathrm{O}_{3} \cdot 6 \mathrm{H}_{2} \mathrm{O}$.

The heavy dashed line ABD is a metastable solubility curve for the "hexagonal" crystalline products of varied $\mathrm{CaO}: \mathrm{Al}_{2} \mathrm{O}_{3}$ ratio. At first thought, the change in the molar ratio of $2 \mathrm{CaO}: \mathrm{Al}_{2} \mathrm{O}_{3}$ (at $\mathrm{A}$ ) to $4 \mathrm{CaO}: \mathrm{Al}_{2} \mathrm{O}_{3}$ (at D) along a smooth solubility curve, with no apparent intervening invariant points, sug- gests a continuous solid solution series. However, X-ray studies indicate that the hexagonal hydrated aluminates along the curve $\mathrm{ABD}$ are more likely intergrown mixtures of the crystals of flat hexagonal plates represented by the end members. To account for the intergrown mixtures of crystals along $\mathrm{ABD}$ the curves QRS and TRV were drawn to indicate approximately the probable true metastable equilibria for $2 \mathrm{CaO} \cdot \mathrm{Al}_{2} \mathrm{O}_{3} \cdot 8 \mathrm{H}_{2} \mathrm{O}$ and $4 \mathrm{CaO} \cdot \mathrm{Al}_{2} \mathrm{O}_{3} \cdot 13 \mathrm{H}_{2} \mathrm{O}$. However, it is more convenient to refer to the overlapping curve $\mathrm{ABD}$ as the metastable equilibrium curve of the hexagonal hydrated aluminates.

The curve PUB, taken from figure 5, represents the solubility of the form of hydrated alumina herein termed microcrystalline gibbsite, or $\mathrm{Al}_{2} \mathrm{O}_{3}$. aq. It is metastable with respect to macrocrystalline gibbsite, $\mathrm{Al}_{2} \mathrm{O}_{3} \cdot 3 \mathrm{H}_{2} \mathrm{O}$, the solubility of which is represented by the curve HFJ. $B$ is a metastable invariant point between $\mathrm{Al}_{2} \mathrm{O}_{3} \cdot \mathrm{aq}$ and hexagonal hydrated aluminate, presumably $2 \mathrm{CaO} \cdot \mathrm{Al}_{2} \mathrm{O}_{3} \cdot 8 \mathrm{H}_{2} \mathrm{O}$. The other metastable invariant is $\mathrm{U}$, which occurs at the intersection of PUB with EF, the metastable portion of the curve EFV for $3 \mathrm{CaO} \cdot \mathrm{Al}_{2} \mathrm{O}_{3} \cdot 6 \mathrm{H}_{2} \mathrm{O}$. It occurs at a higher concentration of alumina in solution than does $\mathrm{F}$, the stable invariant point.

The solubility relationships of the CA-hydrate, so far as is known, have not yet been investigated. For the present the reasonable assumption will be made that the approximate curve $\mathrm{ABD}$ will apply to the CA-hydrate as well as to the other hexagonal hydrates.

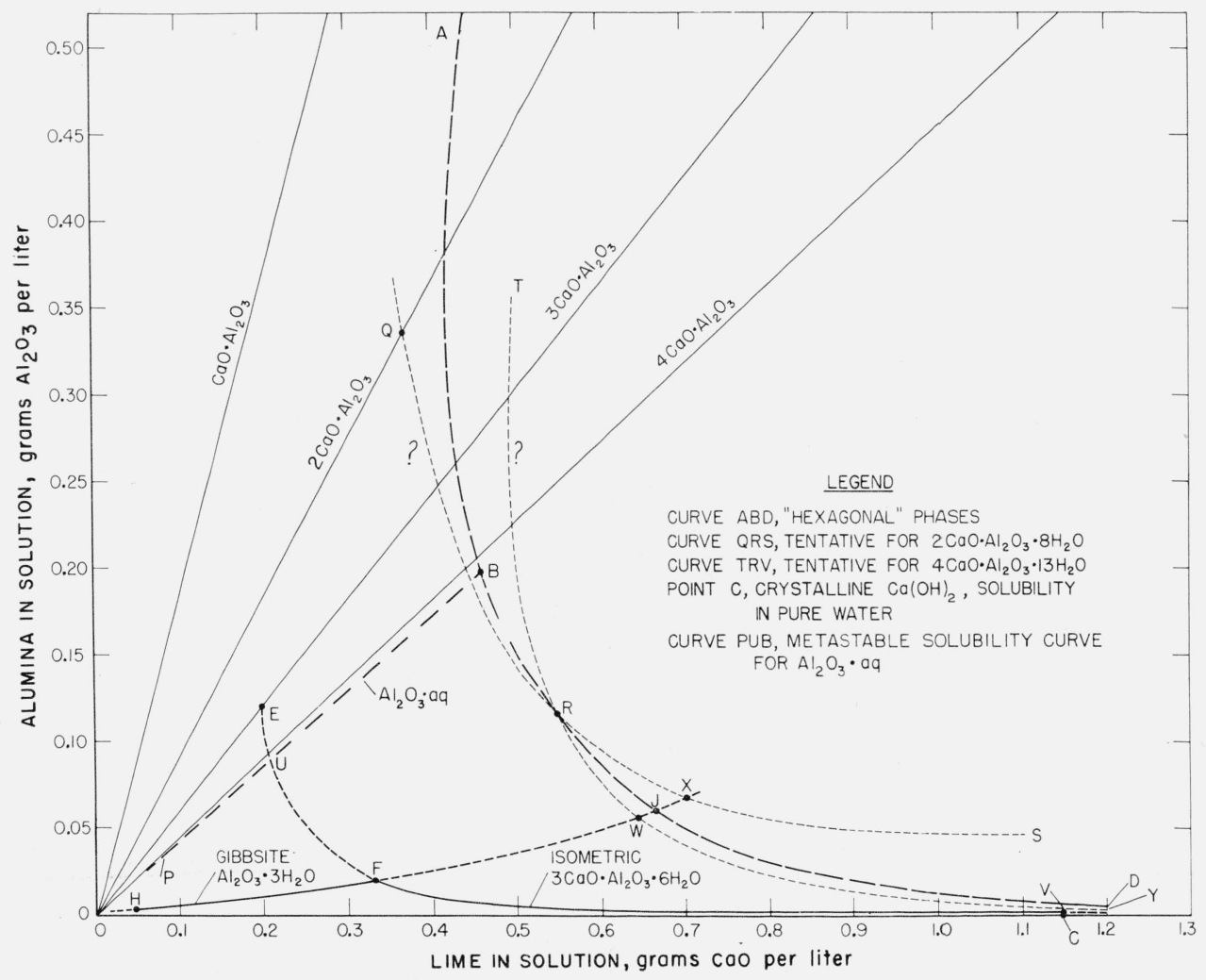

Figure 6. The system $\mathrm{CaO}-\mathrm{Al}_{2} \mathrm{O}_{3}-\mathrm{H}_{2} \mathrm{O}$ at $21^{\circ} \mathrm{C}$. 


\section{Reaction of Water With Calcium Alumi- nates and Aluminous Cements in Rela- tion to the Phase Equilibrium Diagram}

The region where the setting and hardening of calcium aluminates and aluminous cements occurs is shown in figures 1 and 3 . In figure 7 this region is represented by the crosshatched area superimposed upon the phase equilibrium diagram $\mathrm{CaO}-\mathrm{Al}_{2} \mathrm{O}_{3}-\mathrm{H}_{2} \mathrm{O}$.

It should be noted that the superimposed area is long and narrow, and that from $\mathrm{A}^{\prime}$ to $\mathrm{A}$ it closely parallels the $\mathrm{CaO} \cdot \mathrm{Al}_{2} \mathrm{O}_{3}$ composition line. From $\mathrm{A}$ to $\mathrm{B}$ it curves, following more or less the curved section $\mathrm{AB}$ of the curve $\mathrm{ABD}$, which pertains to the metastable hexagonal hydrated calcium aluminates. In general, the area lies to the right of the curve $\mathrm{ABD}$. The solutions within this area contain more than $0.4 \mathrm{~g}$ of $\mathrm{CaO}$ per liter.

The high degree of supersaturation attained by the calcium aluminate solutions during the early stages of the reaction of water with anhydrous calcium aluminates and aluminous cements is evident.

Le Chatelier [26] postulated that the setting of cementitious materials involves the formation of solutions approximately saturated with respect to the anhydrous phase, but supersaturated with respect to the less soluble hydrated phase or phases. The subsequent precipitation of the hydrated phases is, therefore, an important factor attending the processes of setting and hardening. In the case of the calcium aluminates and aluminous cements, the approach to

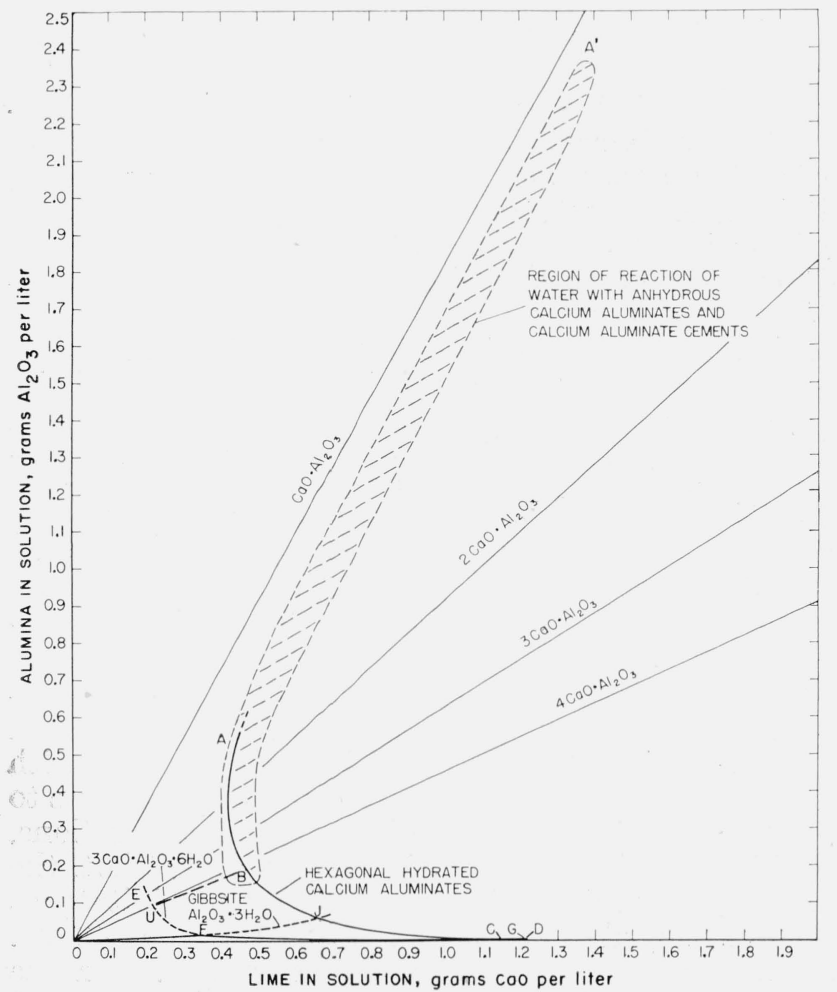

Figure 7. Region of setting of aluminous cements in relation to the phase equilibrium diagram of the system $\mathrm{CaO}-\mathrm{Al}_{2} \mathrm{O}_{3}$ $\mathrm{H}_{2} \mathrm{O}$ at $21^{\circ} \mathrm{C}$. final equilbrium is stepwise; first, a fairly rapid approach to a metastable state (B) followed, second, by a slower change to a stable state $(\mathrm{F})$. Thus, the initial changes in respect to the lime and alumina take place in the area indicated by $\mathrm{A}^{\prime} \mathrm{AB}$, figure 7 , while the later changes occur within the area UFJB.

It should be recalled that $\mathrm{Ca}(\mathrm{OH})_{2}$ occurs as a solid phase in the system $\mathrm{CaO}-\mathrm{Al}_{2} \mathrm{O}_{3}-\mathrm{H}_{2} \mathrm{O}$ at $21^{\circ} \mathrm{C}$ in the vicinity of $\mathrm{C}$, figure $7(1.15 \mathrm{~g}$ of $\mathrm{CaO}$ per liter). From the diagram it can be seen that the products formed in the setting and hardening of the cementitious aluminates are at concentrations of lime far more dilute than this. Consequently, $\mathrm{Ca}(\mathrm{OH})_{2}$ is not formed as a solid phase from the calcium aluminates or calcium aluminate cements. In contrast, $\mathrm{Ca}(\mathrm{OH})_{2}$ is formed as a solid phase in the hydration of portland cement.

The hydrated-alumina phase has been discussed above. There remain to be considered the hexagonal hydrated aluminates. Most of the early investigators in this field concluded that the hexagonal plates they observed were a $\mathrm{C}_{3} \mathrm{~A}$-hydrate. Later work by Lafuma [27], Assarsson [16], Dubuisson [28], and others has afforded ample evidence that, in the area under consideration, the hexagonal phase precipitated is a $\mathrm{C}_{2} \mathrm{~A}$-hydrate. Support for this conclusion may be drawn from the data of Wells, Clarke, and McMurdie [6] from which the curve ABD was constructed.

In general, the $\mathrm{C} / \mathrm{A}$ molar ratio in the precipitate increased from 2 to 4 as the $\mathrm{CaO}$ remaining in solution increased. There were no extensive sections along the curve $\mathrm{ABD}$, where the $\mathrm{CA}$ ratio of the solid phases was exactly $2.0,3.0$, or 4.0 , such as would characterize a series of separate and distinct solubility curves of a hydrated dicalcium, tricalcium, or tetracalcium aluminate. It is significant, however, that all of the initial solutions having molar ratios, $\mathrm{CaO} / \mathrm{Al}_{2} \mathrm{O}_{3}$, less than 2 gave rise to precipitates having molar ratios that approximated 2 . Initial solutions having molar ratios greater than 2.1 produced precipitates having molar ratios less than the respective original solutions. Those initial solutions whose compositions were either on or very close to the $3 \mathrm{CaO} \cdot \mathrm{Al}_{2} \mathrm{O}_{3}$ composition line yielded solid phases whose molar ratios, $\mathrm{CaO} / \mathrm{Al}_{2} \mathrm{O}_{3}$, were much less than 3 (ranging from 2.20 to 2.32 ).

Steinour [8] plotted the C/A ratio for the solid phases against distance along curve $\mathrm{ABD}$, using the data obtained by Wells, Clarke, and McMurdie. A similar graph, based on the same data, is shown in figure 8 , where the $\mathrm{C} / \mathrm{A}$ ratio of the precipitate is plotted against the lime or alumina in solution. The curve shows the abruptness of the transition between solids having the approximate compositions $2 \mathrm{CaO}$. $\mathrm{Al}_{2} \mathrm{O}_{3} \cdot \mathrm{aq}$ and $4 \mathrm{CaO} \cdot \mathrm{Al}_{2} \mathrm{O}_{3}$.aq. It may be noted that when the $\mathrm{C} / \mathrm{A}$ ratio in the solid phase more nearly approaches 2.0 the concentration of both the lime and alumina ranges from about 0.4 to $0.5 \mathrm{~g}$ per liter. This is in the region of $\mathrm{A}$ in figure 6 .

The curve fails to give any evidence of the existence of a distinct hexagonal $\dot{\mathrm{C}}_{3} \mathrm{~A}$-hydrate. This is in accord with the conclusion drawn from the $\mathrm{X}$-ray evidence [6]. 


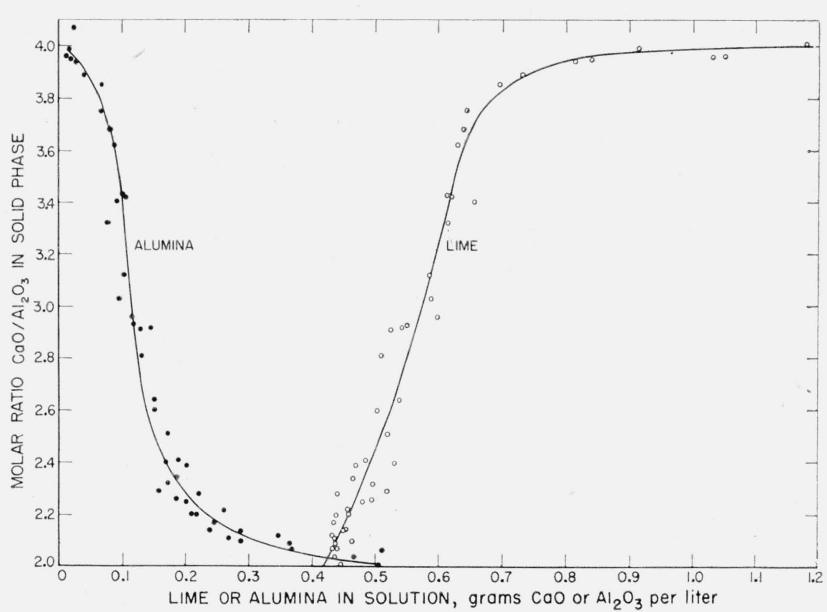

Figure 8. Molar ratio of $\mathrm{CaO}$ to $\mathrm{Al}_{2} \mathrm{O}_{3}$ in the solid phases as a function of composition of the solution in the system $\mathrm{CaO}$ $\mathrm{Al}_{2} \mathrm{O}_{3}-\mathrm{H}_{2} \mathrm{O}$ at $21^{\circ} \mathrm{C}$.

On the basis of the foregoing it appears that the hexagonal phase precipitating in the area $\mathrm{A}^{\prime} \mathrm{AB}$, figure 7 , is the $\mathrm{C}_{2} \mathrm{~A}$-hydrate. From various lines of evidence this conclusion may be considered well established, insofar as it pertains to aluminous cements treated with a relatively large volume of water at room temperature. On the other hand, there is evidence that another hexagonal phase, the CA-hydrate, may be formed during the hydration of aluminous-cement pastes. This is considered further in the following section.

\section{Effect of Temperature on the Hydration of Calcium Aluminates and Aluminous Cements}

\subsection{Theoretical Considerations}

Up to this point the mechanism of the reaction of water on calcium aluminates and the region where the reactions occur have been discussed primarily in relation to the system $\mathrm{CaO}-\mathrm{Al}_{2} \mathrm{O}_{3}-\mathrm{H}_{2} \mathrm{O}$ at $21^{\circ} \mathrm{C}$. The effect of temperature on hydrated calcium aluminates and calcium aluminate cements involves not only consideration of shifts in the solubility curves but also changes that may occur in the hydrated phases.

It is well known that if aluminous cements are hydrated at elevated temperatures (in excess of $35^{\circ}$ C) or are subsequently exposed to such temperatures the strength of the concrete is affected adversely, especially if the concrete is kept moist. It has been suggested by Lea $[29,30]$ and others that the fall in strength may be caused by formation of cubic $3 \mathrm{CaO}$. $\mathrm{Al}_{2} \mathrm{O}_{3} \cdot 6 \mathrm{H}_{2} \mathrm{O}$. In an investigation of the mechanism of the fall in strength of set high-alumina cement at temperatures above normal, Lea also showed that a similar fall in strength occurs with monocalcium aluminate. This was ascribed to a transformation of the metastable less-basic hydrated aluminates into the stable tricalcium aluminate hexahydrate.

The above hypothesis is in agreement with the conclusions drawn by Wells, Clarke, and McMurdie [6] from their study of the system $\mathrm{CaO}-\mathrm{Al}_{2} \mathrm{O}_{3}-\mathrm{H}_{2} \mathrm{O}$.
In that investigation it was shown that the hexagonal hydrates initially formed are metastable with respect to $\mathrm{C}_{3} \mathrm{AH}_{6}$, but that the transformation to the stable form is extremely slow at $21^{\circ} \mathrm{C}$. Lea [30] discussed the likelihood of the formation of a monocalcium aluminate gel at lower temperatures, followed by the conversion to $2 \mathrm{CaO} \cdot \mathrm{Al}_{2} \mathrm{O}_{3} \cdot 8 \mathrm{H}_{2} \mathrm{O}$ and hydrated alumina at ordinary temperatures and the ultimate transition of $\mathrm{C}_{2} \mathrm{AH}_{8}$ to $\mathrm{C}_{3} \mathrm{AH}_{6}$ at higher temperatures. The diagram $\mathrm{CaO}-\mathrm{Al}_{2} \mathrm{O}_{3}-\mathrm{H}_{2} \mathrm{O}$ has not been worked out at temperatures below $21^{\circ} \mathrm{C}$.

Peppler and Wells [7] recently made a study of the system $\mathrm{CaO}-\mathrm{Al}_{2} \mathrm{O}_{3}-\mathrm{H}_{2} \mathrm{O}$ at temperatures ranging from $50^{\circ}$ to $250^{\circ} \mathrm{C}$. They found the hexagonal hydrates to be increasingly unstable at the higher temperatures. At $90^{\circ} \mathrm{C}, \mathrm{C}_{3} \mathrm{AH}_{6}$ began to form within the first hour. At $120^{\circ} \mathrm{C}$ and higher, the hexagonal hydrates were completely supplanted by $\mathrm{C}_{3} \mathrm{AH}_{6}$.

The evidence clearly indicates that the hexagonal $\mathrm{C}_{2} \mathrm{~A}$-hydrate is converted to the more stable $\mathrm{C}_{3} \mathrm{AH}_{6}$ at a rate that increases rapidly with temperature. Thus, there are ample grounds to support the belief that the transformation of the metastable hexagonal $\mathrm{C}_{2} \mathrm{AH}_{8}$ to the stable isometric $\mathrm{C}_{3} \mathrm{AH}_{6}$ is a factor of moment in explaining the retrogression in strength of hydrated calcium aluminates and hydrated aluminous cements as the temperature is raised.

Nevertheless, another very important factor that seems not to have been considered is the transformation of gelatinous hydrated alumina, $\mathrm{Al}_{2} \mathrm{O}_{3} \cdot \mathrm{aq}$ into macrocrystalline gibbsite, $\mathrm{Al}_{2} \mathrm{O}_{3} \cdot 3 \mathrm{H}_{2} \mathrm{O}$, with a resultant loss in its binding properties.

It has long been proposed that the cementing properties of portland cements are inseparably allied to the binding power of colloidal or gelatinous hydrated calcium silicates formed during the process of setting and hardening. In an analogous manner, it is here suggested that the setting and hardening of calcium aluminates and aluminous cements is brought about to a considerable extent by the formation of colloidal or gelatinous hydrated alumina, which may be the principal "inorganic glue." Any factor that would alter the inherent characteristics of such a gel-like material should in turn be reflected in a change in the properties of the hydrated aluminates or cements.

For example, it is known that the temperature of formation, and the temperature at which hydrated alumina gels are maintained, greatly affect the properties of the gels. Furthermore, if the temperature is sufficiently high, gels may not be formed, but instead a macrocrystalline product. Thus, in the familiar Bayer process for the extraction of alumina from bauxite, it is recognized that if the extraction with sodium hydroxide is done at elevated temperatures to produce supersaturated sodium aluminate solutions, and if the solutions thus produced are kept hot, the hydrated alumina will subsequently precipitate as well-developed crystals of gibbsite, $\mathrm{Al}_{2} \mathrm{O}_{3} \cdot 3 \mathrm{H}_{2} \mathrm{O}$. Such crystals can be filtered and washed. On the other hand, if the supersaturated solutions are not kept hot, then a more gelatinous hydrated alumina is formed. 
The same principle applies to the calcium aluminates. The latter, however, being much less soluble, do not produce the high alkalinity necessary for rapid conversion to macrocrystalline gibbsite.

It was shown previously that, in the reaction between water and aluminous cement at $21^{\circ} \mathrm{C}$, a metastable solution is formed having approximately the composition indicated by point $\mathrm{B}$ in figure 7 . The concentration at this point is $0.19 \mathrm{~g}$ of $\mathrm{Al}_{2} \mathrm{O}_{3}$ and $0.46 \mathrm{~g}$ of $\mathrm{CaO}$ per liter. The $p \mathrm{H}$ is about 11.75 , representing a concentration of $\mathrm{Ca}(\mathrm{OH})_{2}$ (in excess of the monocalcium aluminate in solution) equivalent to $0.35 \mathrm{~g}$ of $\mathrm{CaO}$ per liter. At point $\mathrm{F}$ it is slightly lower. The concentration at saturation is $1.15 \mathrm{~g}$ per liter. Thus the aging of the hydrated alumina, at $21^{\circ} \mathrm{C}$, takes place in a $\mathrm{Ca}(\mathrm{OH})_{2}$ solution only about one-third saturated.

At higher temperatures the concentration of $\mathrm{CaO}$ at the invariant point remains about the same. Thus, Peppler and Wells [7] found that at $50^{\circ}$ and $120^{\circ}$ the $\mathrm{CaO}$ concentration at the invariant point was about $0.3 \mathrm{~g}$ per liter. Because there is essentially no change in alkalinity as the temperature is raised, the increased rate of change from gelatinous $\mathrm{Al}_{2} \mathrm{O}_{3}$. aq to macrocrystalline gibbsite must be ascribed to a direct effect of increased temperature on the hydrated alumina.

\subsection{Experiments With Cement Pastes Cured at Various Temperatures}

To gain some information as to the nature of the hydration products formed at different temperatures, a few experiments were conducted on hardened cement pastes. Three cements were used: Nos. 4 and 6 (table 1) and an aluminous cement of recent manufacture, designated No. 9. The latter was of the same brand as No. 1 (table 1) but differed considerably from it in composition.

The cement was mixed with water in the ratio $\mathrm{w} / \mathrm{c}=0.38$, and portions of the paste were placed in glass vials and stored under water for 7 days at four different temperatures: $24^{\circ}, 35^{\circ}, 50^{\circ}$, and $80^{\circ} \mathrm{C}$. The specimens then were dried, and surface areas were determined.

X-ray powder diffraction patterns of the hardened pastes were also made. Samples used for this purpose were dried only superficially. By comparison of the patterns with those of the anhydrous cements, it was concluded that much of the cement remained unhydrated after the curing period. The patterns for the anhydrous cements were rather complex, but in both Nos. 4 and 6 there was a series of lines agreeing fairly well with the published patterns for gehlenite, $\mathrm{C}_{2} \mathrm{AS}$. These lines persisted in the hydrated pastes, as would be expected from the known inertness of gehlenite. A few other lines were tentatively ascribed to $\mathrm{CaO} \cdot \mathrm{Al}_{2} \mathrm{O}_{3}$; these disappeared after hydration. By reference to table 1 it may be noted that neither of these cements was expected to contain gehlenite. Thus considerable doubt is cast on the validity of the calculated compositions. This is not necessarily a reflection on the method of calculation;
TABLE 4. Surface areas (by $\mathrm{N}_{2}$ absorption) of aluminouscement pastes cured $\gamma$ days at various temperatures

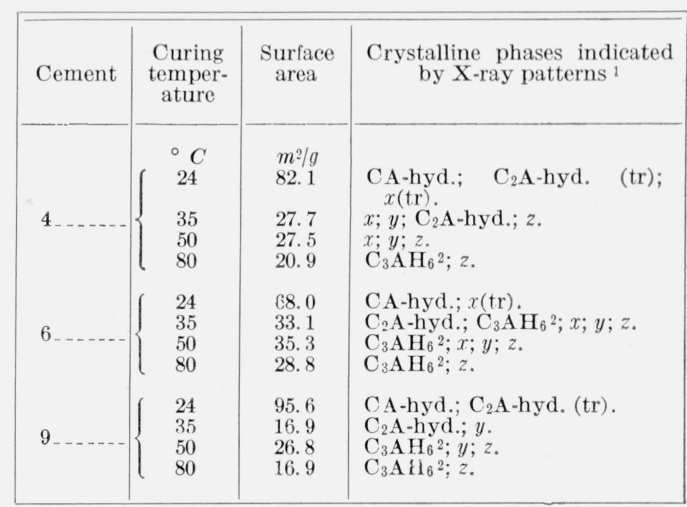

$1 x$ : A hexagonal calcium aluminate hydrate of unknown composition; widest d-spacing about $7.7 \mathrm{~A}$. $y$ : An unknown compound, possibly a hexagonal calcium luminate hydrate; widest $d$-spacing about $12.5 \mathrm{~A}$. $z$ : An unknown compound (possibly gibbsite) represented by a single line at $4.85 \mathrm{~A}$

2 Slight shift in lines indicates that the $\mathrm{C}_{3} \mathrm{AH}_{6}$ contains a small amount of $\mathrm{SiO}_{2}$
possibly gibbite) represented by a single line at $4.85 \mathrm{~A}$. in solid solution.

more likely it indicates that the separation of the insoluble residue, a necessary preliminary step, is very sensitive to small variations in procedure.

Irrespective of assumptions as to the composition of the anhydrous cement, the lines due to the phases formed on hydration in most cases could be distinguished when the patterns were compared. There were, of course, some ambiguities resulting from coincident or overlapping reflections, but these were infrequent at the low-angle end of the pattern. By comparison of the entire series of patterns, no less than six distinct sets (or partial sets) of lines could be distinguished, representing the phases listed in the last column of table 4 . These will be considered separately.

(1) Lines of the cubic $\mathrm{C}_{3} \mathrm{AH}_{6}$ were readily discerned in the patterns of all three cements cured at $80^{\circ}$, in two cured at $50^{\circ}$, and in one cured at $35^{\circ}$ (trace only). In most cases the lines were displaced slightly toward higher angles, presumably by the presence of $\mathrm{SiO}_{2}$ in solid solution, and in a few instances there was evidence of a double hydrogarnet pattern. The significance of these displacements has been discussed in a recent paper [31].

(2) The $\mathrm{C}_{2} \mathrm{~A}$-hydrate could be identified by the lines at approximately 10.6 and $5.3 \mathrm{~A}$, representing its widest $d$-spacings. It occurred in all three pastes cured at $35^{\circ}$, and as traces in two cured at $24^{\circ}$.

(3) The phase designated CA-hydrate was identified by the lines at about 14.6 and $7.3 \mathrm{~A}$, in agreement with the pattern given by Longuet [21]. It was the predominant phase in all three cements cured at $24^{\circ}$, but was not present at higher temperatures.

(4) The phase designated $x$ gives a pattern identical with some recently obtained in this laboratory for a precipitated calcium aluminate hydrate of uncertain composition. It is similar to the pattern of $\mathrm{C}_{4} \mathrm{~A}$-hydrate, but the $d$-spacings of the first two lines are distinctly smaller (about 7.7 and $3.85 \mathrm{~A}$ ) than those reported by McMurdie [6] for the $\mathrm{C}_{4} \mathrm{~A}$-hydrate. It may tentatively be considered a less-basic calcium aluminate hydrate. It was observed in the hydrated 
pastes of cements 4 and 6 at the three lower temperatures, and in two cases was the predominant phase.

(5) The pattern of phase $y$ was relatively weak, and was defined only by lines at about 12.5 and 6.25 A. It is thus similar to the patterns of the known hexagonal aluminates (and phase $x$ ) in having two low-angle reflections, the second at one-half the $d$-spacing of the first. Phase $y$ was observed in all three pastes cured at $35^{\circ}$ and $50^{\circ}$.

(6) Presence of a phase designated $z$ was inferred from the occurrence of a single line at about $4.85 \mathrm{~A}$ in the patterns of all the pastes cured at $50^{\circ}$ and $80^{\circ}$, and (in smaller amounts) in two cured at $35^{\circ}$. Although this is insufficient for the purpose of identification, it should be noted that the position is that of the predominant line of gibbsite. Reflections corresponding to the less prominent lines of gibbsite were also observed, but they either were very weak or occurred in positions where they might reasonably be attributed to some other phase. Thus the evidence for identifying phase $z$ with gibbsite remains inconclusive.

The X-ray data may now be summarized as follows: (a) Some unhydrated cement constituents remain after 7 days curing, the amount decreasing as the curing temperature is increased. (b) CA-hydrate is formed at $24^{\circ}$. (c) At intermediate temperatures, $\mathrm{C}_{2} \mathrm{~A}$-hydrate and two other phases, at least one of which is a hydrated calcium aluminate, are formed. (d) At higher temperatures, $\mathrm{C}_{3} \mathrm{AH}_{6}$, probably containing a little $\mathrm{SiO}_{2}$, is formed; also an unknown phase that may be gibbsite. (e) The three cements are essentially similar in behavior although minor differences exist.

Surface areas of the hardened pastes were determined by nitrogen absorption, using a procedure described by Emmett [32]. ${ }^{4}$ The samples were first crushed and vacuum dried for a week at room temperature. The surface areas found are given in table 5. In comparing the data it should be borne in mind that none of the pastes were completely hydrated, and that the degree of hydration increased with temperature. Hence, in the absence of other effects, an increase in surface area with temperature would have been expected. There is, instead, a sharp decrease, most of which occurs between $24^{\circ}$ and $35^{\circ} \mathrm{C}$. The correlation between high surface area and the predominance of CA-hydrate in the set cement is readily apparent. Aside from this, the relations are too complex to warrant any definite conclusions. The data fail to show any marked decrease in surface area attending the formation of the cubic $\mathrm{C}_{3} \mathrm{AH}_{6}$. As to the suggested role of the aging of $\mathrm{Al}_{2} \mathrm{O}_{3}$.aq, the data provide no definite information.

\section{Summary}

A study was made of the reaction of water at room temperature on eight aluminous cements of different compositions. The results were compared with data previously obtained from similar tests on the calcium aluminates. Despite the wide variation in compound

\footnotetext{
${ }_{4}^{4}$ The surface area determinations were made by C.M. Hunt and V. Dantzler.
}

composition, as calculated by the method of Parker, the cements were remarkably similar in their reaction with water. Like the three calcium aluminates less basic than $3 \mathrm{CaO} \cdot \mathrm{Al}_{2} \mathrm{O}_{3}$, the aluminous cements produced supersaturated calcium aluminate solutions in which the molar ratio of $\mathrm{CaO}$ to $\mathrm{Al}_{2} \mathrm{O}_{3}$ was slightly greater than 1 to 1 . The metastable solutions, originating from the pure calcium aluminates, decreased in concentration rather rapidly as solid phases precipitated out, until a "steady state" was reached at a concentration of approximately 0.16 $\mathrm{g}$ of $\mathrm{Al}_{2} \mathrm{O}_{3}$ and $0.46 \mathrm{~g}$ of $\mathrm{CaO}$ per liter. Solutions from the aluminous cements similarly reached an average concentration of $0.19 \mathrm{~g}$ of $\mathrm{Al}_{2} \mathrm{O}_{3}$ and $0.46 \mathrm{~g}$ of $\mathrm{CaO}$ per liter. In both cases the precipitate consisted chiefly of a hexagonal calcium aluminate hydrate, $2 \mathrm{CaO} \cdot \mathrm{Al}_{2} \mathrm{O}_{3} \cdot 8 \mathrm{H}_{2} \mathrm{O}$, and an apparently amorphous form of hydrated alumina designated $\mathrm{Al}_{2} \mathrm{O}_{3}$.aq. Small amounts of the isometric hydrate, $3 \mathrm{CaO} \cdot \mathrm{Al}_{2} \mathrm{O}_{3} \cdot 6 \mathrm{H}_{2} \mathrm{O}$, were also found in some instances. The precipitation process was accompanied by an increase in $p \mathrm{H}$ from about 11.25 to about 11.7 , even though the total $\mathrm{CaO}$ in solution was decreasing. This is in agreement with the results given in an earlier paper, in which it was shown that the alumina exists in solution as monocalcium aluminate and that only the $\mathrm{CaO}$ in excess of that combined as monocalcium aluminate is effective in raising the $p \mathrm{H}$.

Calculations based on the assumption that monobasic aluminic acid has an ionization constant of $10^{-10}$ lead to a theoretical value of about 11.25 for the $p \mathrm{H}$ of the hydrolyzed calcium aluminate solution, which is in agreement with the average of the observed values for the solutions obtained in the early stages of the reaction of water on the calcium aluminates and aluminous cements.

The phase equilibrium diagram for the system $\mathrm{CaO}-\mathrm{Al}_{2} \mathrm{O}_{3}-\mathrm{H}_{2} \mathrm{O}$ at $21^{\circ} \mathrm{C}$ indicates three stable phases: gibbsite $\left(\mathrm{Al}_{2} \mathrm{O}_{3} \cdot 3 \mathrm{H}_{2} \mathrm{O}\right), 3 \mathrm{CaO} \cdot \mathrm{Al}_{2} \mathrm{O}_{3} \cdot 6 \mathrm{H}_{2} \mathrm{O}$, and $\mathrm{Ca}(\mathrm{OH})_{2}$. The invariant point between gibbsite and $3 \mathrm{CaO} \cdot \mathrm{Al}_{2} \mathrm{O}_{3} \cdot 6 \mathrm{H}_{2} \mathrm{O}$ is placed at $0.33 \mathrm{~g}$ of $\mathrm{CaO}$ and $0.02 \mathrm{~g}$ of $\mathrm{Al}_{2} \mathrm{O}_{3}$ per liter. Metastable solubility curves are included for $2 \mathrm{CaO} \cdot \mathrm{Al}_{2} \mathrm{O}_{3} \cdot 8 \mathrm{H}_{2} \mathrm{O}$, $4 \mathrm{CaO} \cdot \mathrm{Al}_{2} \mathrm{O}_{3} \cdot 13 \mathrm{H}_{2} \mathrm{O}$, and a microcrystalline form of hydrated alumina designated $\mathrm{Al}_{2} \mathrm{O}_{3}$.aq. This form of alumina separates from the supersaturated solutions as flakes and minute pellets containing 3 to 4 moles of $\mathrm{H}_{2} \mathrm{O}$ per mole of $\mathrm{Al}_{2} \mathrm{O}_{3}$. The index of refraction, originally about 1.50 , slowly increases to as high as 1.56 , the increase being more rapid at the surface than in the interior of the particles. This study, coupled with the results of X-ray examination by other investigators, leads to the conclusion that the $\mathrm{Al}_{2} \mathrm{O}_{3} \cdot \mathrm{aq}$ is gibbsite in microcrystalline form. Because of its extreme fineness it has a higher solubility than macrocrystalline gibbsite.

The hydration of the less basic calcium aluminates and the aluminous cements occurs in that part of the system $\mathrm{CaO}-\mathrm{Al}_{2} \mathrm{O}_{3}-\mathrm{H}_{2} \mathrm{O}$ in which $2 \mathrm{CaO} \cdot \mathrm{Al}_{2} \mathrm{O}_{3} \cdot 8 \mathrm{H}_{2} \mathrm{O}$ and $\mathrm{Al}_{2} \mathrm{O}_{3}$.aq are precipitated. Both are capable of being transformed to more stable phases; the former to isometric $3 \mathrm{CaO} \cdot \mathrm{Al}_{2} \mathrm{O}_{3} \cdot 6 \mathrm{H}_{2} \mathrm{O}$ plus alumina, the 
latter to macrocrystalline gibbsite. The region of formation of $4 \mathrm{CaO} \cdot \mathrm{Al}_{2} \mathrm{O}_{3} \cdot 13 \mathrm{H}_{2} \mathrm{O}$ is not reached in these hydration processes. The part played by monocalcium aluminate hydrate is still largely undetermined.

Higher temperatures accelerate the transformation of the metastable to the stable solid phases. The rapid conversion of the hexagonal hydrated aluminates to the rounded grains of $3 \mathrm{CaO} \cdot \mathrm{Al}_{2} \mathrm{O} \cdot 6 \mathrm{H}_{2} \mathrm{O}$ is usually considered to be the chief cause of the retrogression in strength undergone by aluminous cements on heating. It is here suggested that the aging of $\mathrm{Al}_{2} \mathrm{O}_{3}$.aq to macrocrystalline gibbsite may be an important factor in the loss of strength at higher temperatures. Experiments with hardened pastes of three aluminous cements indicated that monocalcium aluminate hydrate is the chief hydration product at $24^{\circ} \mathrm{C}$, while tricalcium aluminate hexahydrate predominates at $80^{\circ}$, and a number of other phases are formed at intermediate temperatures. The surface areas of the pastes cured at $24^{\circ} \mathrm{C}$ were much higher than those of pastes cured at higher temperatures.

\section{References}

[1] F. M. Lea and C. H. Desch, The chemistry of cement and concrete, chap. XV and XVI (Edward Arnold \& Co., London, 1935).

[2] R. A. Heindl and Z. A. Post, J. Am. Ceram. Soc. 33, 230 (1950).

[3] P. H. Bates, Tech. Pap. BS 15, (1921) T197.

[4] L. S. Wells, BS J. Research 1,951 (1928) RP34.

[5] P. H. Bates, First Communications Internat. Assoc. Test. Mat., p. 210 (Zurich, 1930).

[6] L. S. Wells, W. F. Clarke, and H. F. MeMurdie, J. Research NBS 30, 367 (1943) RP1539.

[7] R. B. Peppler and L. S. Wells, J. Research NBS 52, 75 (1954) RP2476.

[8] H. H. Steinour, Research and Develop. Labs. Portland Cement Assoc. Bul. 34 (1951).
[9] T. W. Parker, Symposium Chem. Cements, pp. 485529 (London, 1952)

[10] N. Sundius, Symposium Chem. Cements, p. 395 (Stockholm, 1938).

[11] B. Tavasci, Symposium Chem. Cements, p. 422 (Stockholm, 1938).

[12] S. Solacolu, Dissertation (Berlin, 1932).

[13] G. A. Rankin and F. E. Wright, Am. J. Sci. [4] 39, 1 (1915).

[14] H. F. McMurdie, J. Research NBS 18, 475 (1937) RP987.

[15] M. A. Swayze, Am. J. Sci. 244, 1, 65 (1946).

[16] G. Assarsson, Sveriges Geol. Undersökn, 30, Ser. C, No. 399,5 (1936)

[17] L. Forsén, Symposium Chem. Cements, p. 298 (Stockholm, 1938).

[18] R. Hedin, Svenska Forskningsinst. Cement Betong Kungl. Tek. Högsk. No. 3 (Stockholm, 1945).

[19] R. E. Slade, Z anorg. Chem. 7y, 457 (1912).

[20] G. Assarsson, Sveriges Geol. Undersökn [C] 27, No. 379, $22(1933)$

[21] P. Longuet, Symposium Chem. Cements, pp. 328-331 (London, 1952).

[22] J. Brocard, Ann. inst. tech. bâtiment et trav. publ., New Series, No. 12 (Feb. 1948).

[23] G. Assarsson, Z. anorg. allgem. Chem. 222, 321 (1935)

[24] G. E. Bessey, Symposium Chem. Cements, p. 178, 216 (Stockholm, 1938)

[25] J. D'Ans and H. Eick, Zement-Kalk-Gips 6, 197 (1953)

[26] H. LeChatelier, Experimental Researches on the Constitution of Hydraulic Mortars; translated by J. L Mack (McGraw-Hill Book Co., Inc., New York N. Y., 1905).

[27] H. Lafuma, Ciment 30, 174 (1925) ; Dissertation (Paris, 1925).

[28] Dubuisson, 21ème Congr. chim. ind. (Brussels, 1948); Cement Lime Manuf. 22, 37 (1949).

[29] F. M. Lea, Symposium Chem. Cements, p. 459 (Stockholm, 1938)

[30] F. M. Lea, J. Soc. Chem. Ind. (London) 59, 18 (1940)

[31] E. T. Carlson, J. Research NBS 56, 327 (1956) RP2683.

[32] P. H. Emmett, ASTM Symposium on New Methods for Particle Size Determination in the Subsieve Range p. 95 (1941).

Washington, August 9, 1956. 